\title{
Advances in remote sensing applications for urban sustainability
}

\author{
Nada Kadhim $^{1,2}$ (D) Monjur Mourshed $^{1}$ (D) Michaela Bray $^{1}$
}

Received: 5 July 2016/Accepted: 23 September 2016/Published online: 18 October 2016

(c) The Author(s) 2016. This article is published with open access at Springerlink.com

\begin{abstract}
It is essential to monitor urban evolution at spatial and temporal scales to improve our understanding of the changes in cities and their impact on natural resources and environmental systems. Various aspects of remote sensing are routinely used to detect and map features and changes on land and sea surfaces, and in the atmosphere that affect urban sustainability. We provide a critical and comprehensive review of the characteristics of remote sensing systems, and in particular the trade-offs between various system parameters, as well as their use in two key research areas: (a) issues resulting from the expansion of urban environments, and (b) sustainable urban development. The analysis identifies three key trends in the existing literature: (a) the integration of heterogeneous remote sensing data, primarily for investigating or modelling urban environments as a complex system, (b) the development of new algorithms for effective extraction of urban features, and (c) the improvement in the accuracy of traditional spectral-based classification algorithms for addressing the spectral heterogeneity within urban areas. Growing interests in renewable energy have also resulted in the increased use of remote sensing-for planning,
\end{abstract}

Nada Kadhim

MohammedSalihNM@cardiff.ac.uk;

nada.m.kadhim@gmail.com

Monjur Mourshed

MourshedM@cardiff.ac.uk

Michaela Bray

BrayM1@ cardiff.ac.uk

1 Cardiff School of Engineering, Cardiff University, Cardiff CF24 3AA, UK

2 Department of Civil Engineering, University of Diyala, Diyala, Iraq operation, and maintenance of energy infrastructures, in particular the ones with spatial variability, such as solar, wind, and geothermal energy. The proliferation of sustainability thinking in all facets of urban development and management also acts as a catalyst for the increased use of, and advances in, remote sensing for urban applications.

Keywords Remote sensing systems - Remote sensing applications · Environmental sustainability · Urban environments $\cdot$ Sustainable cities

\section{Introduction}

Cities are engines of economic prosperity and social development that arise from the concentration of people and economic activities but often manifests in unsustainable urban environments [57]. Economic opportunities in cities act as a catalyst for rapid urbanisation across the globe. Urbanisation rates are uneven and are much faster in developing countries [7]. By 2030, the annual average rate of urban growth is expected to be $0.04 \%$ in Europe, $1.5 \%$ in the USA, $2.2 \%$ in East Asia and the Pacific, $2.7 \%$ in South Asia, $2.3 \%$ in the Middle East and North Africa, and $3.6 \%$ in Sub-Saharan Africa [80]. Increased urban migration has contributed to the unplanned or poorly planned and implemented growth and expansion of cities. The latter is a critical factor for urban stakeholders as unplanned urban growth can have a long-term negative impact on urban sustainability on a range of scales-local, regional, national, and potentially inter-governmental [75]. Impacts include detrimental economic consequences such as the reduction in the productivity of key economic sectors [18]; environmental degradation such as poor air quality, and increased urban temperatures and surface run-off 
[53, 85, 87]; and negative societal impacts such as increased morbidity and mortality, negative impacts on quality of life, and the fragmentation of neighbourhoods and related communities [29].

The effective management of the risks arising from the reformation of urban landscapes and related environmental systems requires evidence-based approaches for mitigating and adapting to the undesirable changes. Gathering evidence of urban change is typically a time and resource intensive process that needs the application of appropriate technologies to identify arising risks. Recent advances in satellite remote sensing offer opportunities to cost-effectively monitor urban change and its impact on the complex urban socio-technical systems and enable stakeholders to make informed decisions to reduce negative impacts on the environment. Remotely sensed data are an important and powerful source of information on urban morphology and changes over time [64]. In contrast, conventional observation techniques are often logistically constrained in that they require a great deal of effort, cost, and time to obtain information over a large spatial expanse in a consistent manner [52]. The lower cost and availability of data have facilitated the way researchers accomplish research objectives, and have fostered public engagement with remote sensing science.

There is a growing body of literature on the application of urban remote sensing-from the investigation on landcover and land-use changes to the monitoring of microclimatic parameters and the assessment of renewable energy potential. Increased vulnerabilities from the impacts of climate change and disaster risks, and urban growth resulting from rapid urbanisation have influenced recent developments on integrated risk modelling that combine remote sense analysis with social and economic data for urban sustainability assessment [57]. Collaboration between expert stakeholders is essential to realise the full potential offered by remote sensing for urban sustainability [64]. Yet, there is a lack of understanding among urban professionals of the technical characteristics of remotely sensed data and their suitability for analysis, limitations, and potential for application. We aim to address the gaps in understanding by critically reviewing the technical characteristics of available remote sense sources and their applications for urban sustainability. The findings will act as a comprehensive resource on the state-of-the-art, and provide directions for future research.

Following the introduction, the paper is divided into three sections. First, existing remote sensing systems and available satellite data resources are reviewed and categorised to provide the context for subsequent discussions. The information will also act as an indispensable resource for urban professionals in identifying appropriate remote sensing data for specific applications. Second, a state-of- the-art review is presented on the applications of remote sensing in urban sustainability. Third, the limitations of the reviewed applications are highlighted with a discussion on future directions for research and development.

\section{Remote sensing systems and satellite data resources}

Three distinct stages of the development of remote sensing (RS) instruments are illustrated in Fig. 1. The first generation RS instruments were of low spatial resolution, $1 \mathrm{~km}-100 \mathrm{~m}$, increasing to $30-10 \mathrm{~m}$ in the second generation. The third generation instruments are more capable in observing the Earth's surface with a very high spatial resolution, 5-0.5 m and less, enabling the acquisition of further spatial detailsresulting in more accurate feature recognition. To enable the reader to gain a high-level overview of RS characteristics, we categorised the satellites based on their orbit; sensor mode and instrument; resolution; and wavelength of electromagnetic radiation (EMR), as shown in Fig. 2.

\section{Orbit}

RS satellites roam in the two kinds of orbits: sun-synchronous and geostationary. Most RS platforms, such as Landsat, SPOT and IKONOS, operate in a near-polar (i.e. sun-synchronous) orbit at low altitudes and pass over each area before noon, at 10:30 am local time [62], allowing the acquisition of clearer images of the Earth's surface over a particular area on a series of days in similar illumination conditions; i.e. when the sun position is optimal, between 9.30 and 11.30 am local time [13]. In contrast, geostationary satellites are ideal for some communication and meteorological applications because of their very high altitudes allowing continuous coverage of a large area of the Earth's surface, with the trade-off being low spatial resolution.

\section{Sensor mode and instrument}

Spatial resolution is based on pixel size and is said to be low when it is greater than $100 \mathrm{~m}$, medium when between 10 and $100 \mathrm{~m}$, and high when it is less than $10 \mathrm{~m}$ [66]. Depending on the on-board sensor's spatial resolution, RS systems can be classified into two groups: low and medium, and high and very high. Existing low-medium, and high-very high RS systems and their potential applications are given in Tables 1 and 2, respectively. Most of the data are available at a low cost, and often free to download on the Internet. A summary of selected websites for downloading satellite imagery, radar, LiDAR, hyperspectral, aerial orthoimagery and digital spectral library data are presented in Table 3. 


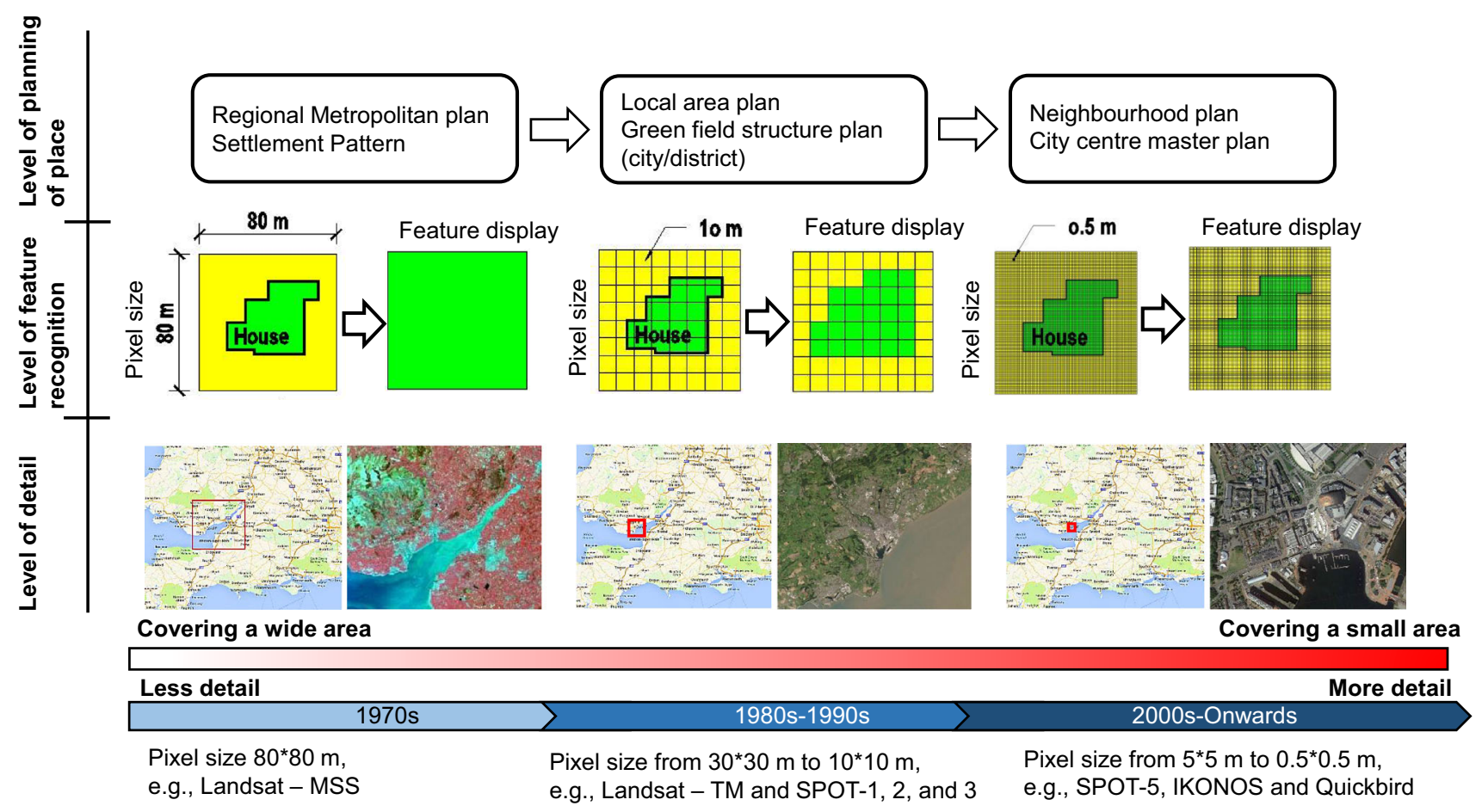

Fig. 1 A comparison of satellite generations in terms of detail, feature recognition and planning requirements. The red square represents the spatial resolution of the adjacent RS image. An image with a pixel size of $80 \mathrm{~m}$ (Landsat-MSS) cannot recognise an object, such as a house but its features can be effectively recognised with a pixel size of $0.6 \mathrm{~m}$ (QuickBird)
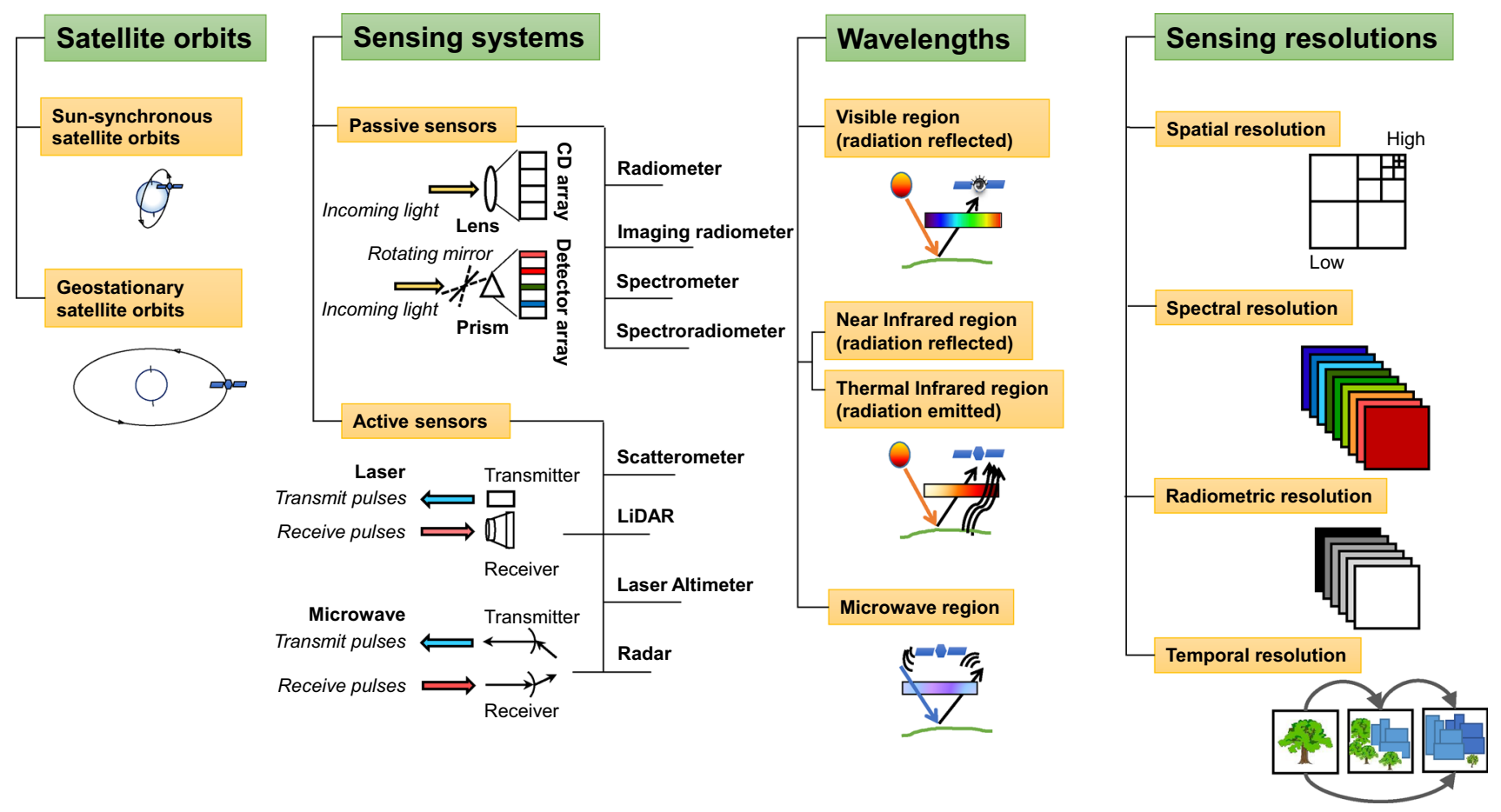

Fig. 2 Classification of remote sensing sensors based on their characteristics 


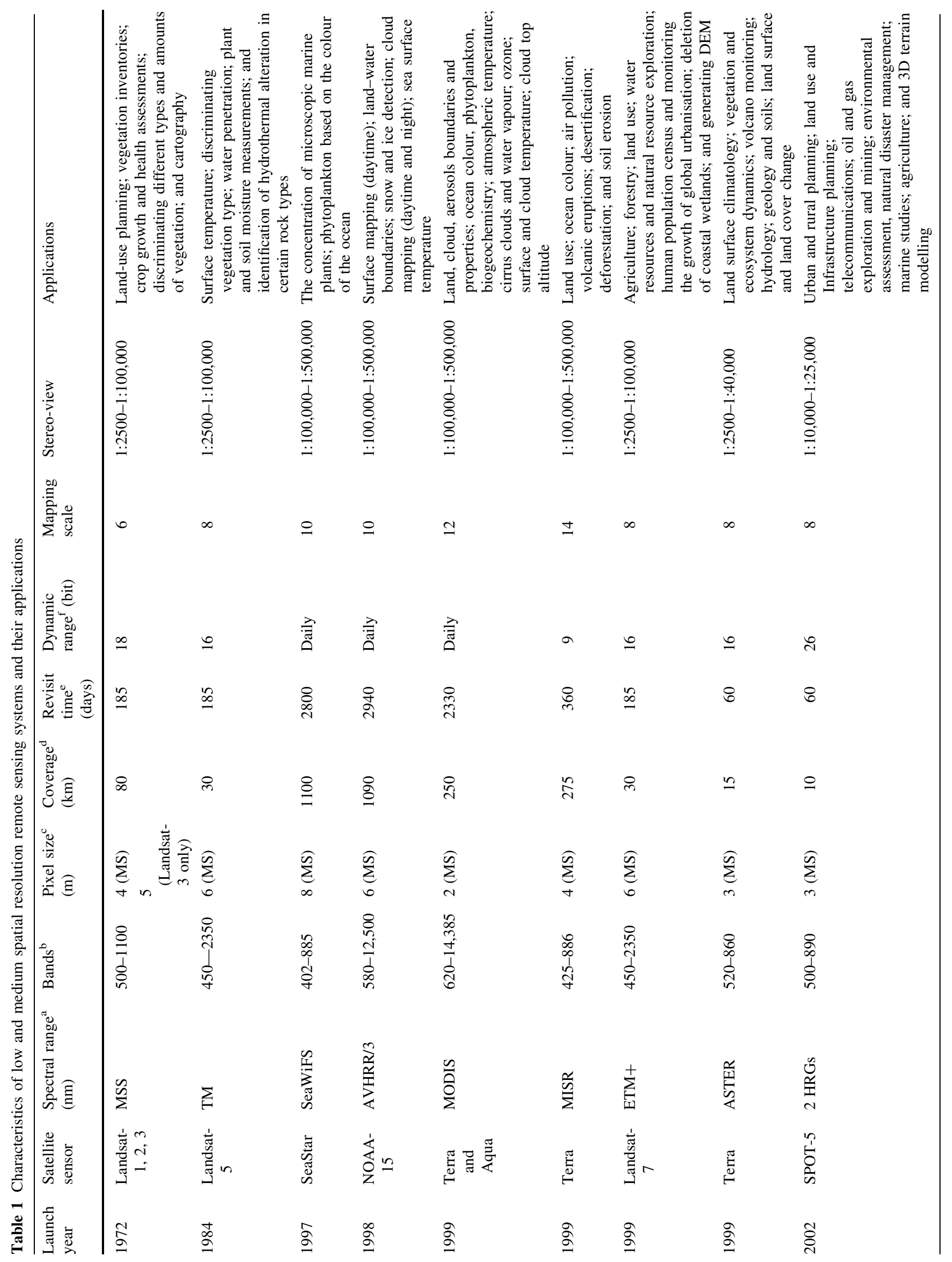




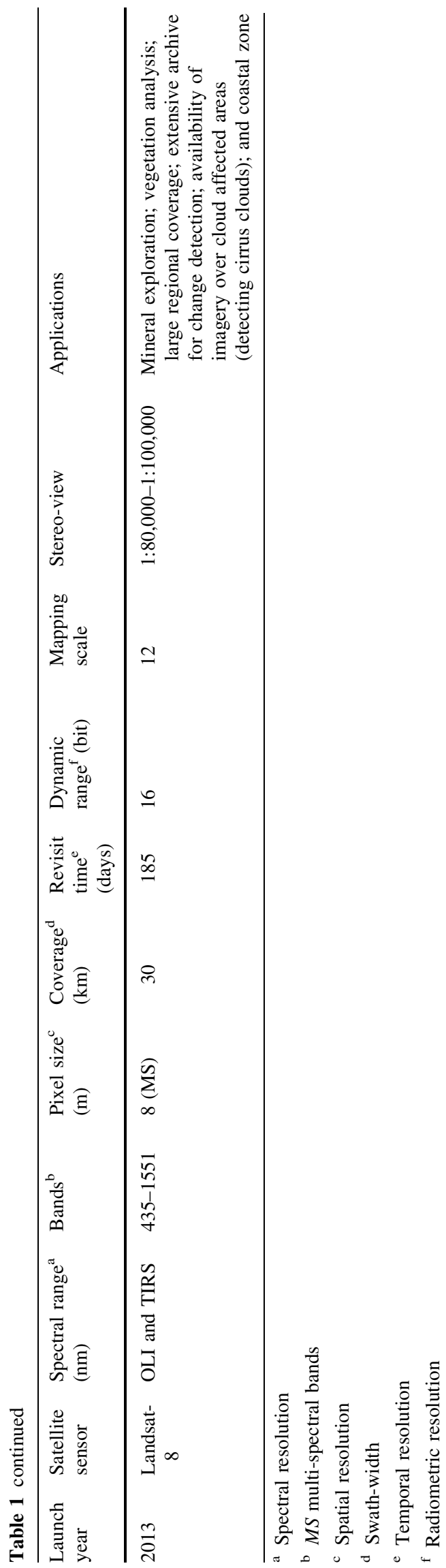

\section{Resolution}

The trade-off between spatial and temporal resolution need to be reconciled for the selection of satellite images for a particular application, as illustrated in Fig. 3. For instance, a high temporal resolution is essential for emergency situations, such as landfall due to hurricanes, because emergency situations change rapidly and require frequent observations on the day. In contrast, urban infrastructure planning applications require spatial understanding over a longer period, for which annual observations are often sufficient. However, both use cases sometimes require high spatial resolution images to observe their processes comprehensively. On the other hand, high temporal resolution is required for applications such as weather that changes rapidly. Operational weather forecast, therefore, requires satellite observations with high temporal resolution often at the cost of spatial resolution. Each RS application, thus, has its own unique resolution requirements which need to be appreciated.

\section{Remote sensing of urban environments}

Cities are unique because of the existence of dense artificial structures. The increasing urbanisation rate will eventually lead to the expedited consumption of non-renewable land resources such as water (on- and under-ground) and food [49], and energy resources such as oil, coal and gas-with environmental, social and economic impact on developing and developed countries alike [3]. Thus, the growth of urban areas can result in substantial land-cover and landuse changes - an ideal sustainability use case for the use of remote sensing. The next sections are devoted to review of remote sensing applications within urban environments, focussing on urban growth, sprawl and change; environmental impacts of urban growth; and sustainable energy applications.

\section{Urban growth, sprawl and change}

Urban growth refers to the transformation of the landscape from undeveloped to developed land [7]. More specifically, the growth away from central urban areas into homogeneous, low-density and typically car-dependent communities is often referred to as urban/suburban sprawl. In developing countries, urban sprawl can be unplanned and uncontrolled [9]. Consequently, urban growth leads to the loss of farmland, gives rise to economic and social issues, and increases water and energy consumption, and associated greenhouse gas emissions [25]. From stakeholders' point of view, the expansion of cities is a crucial change in 


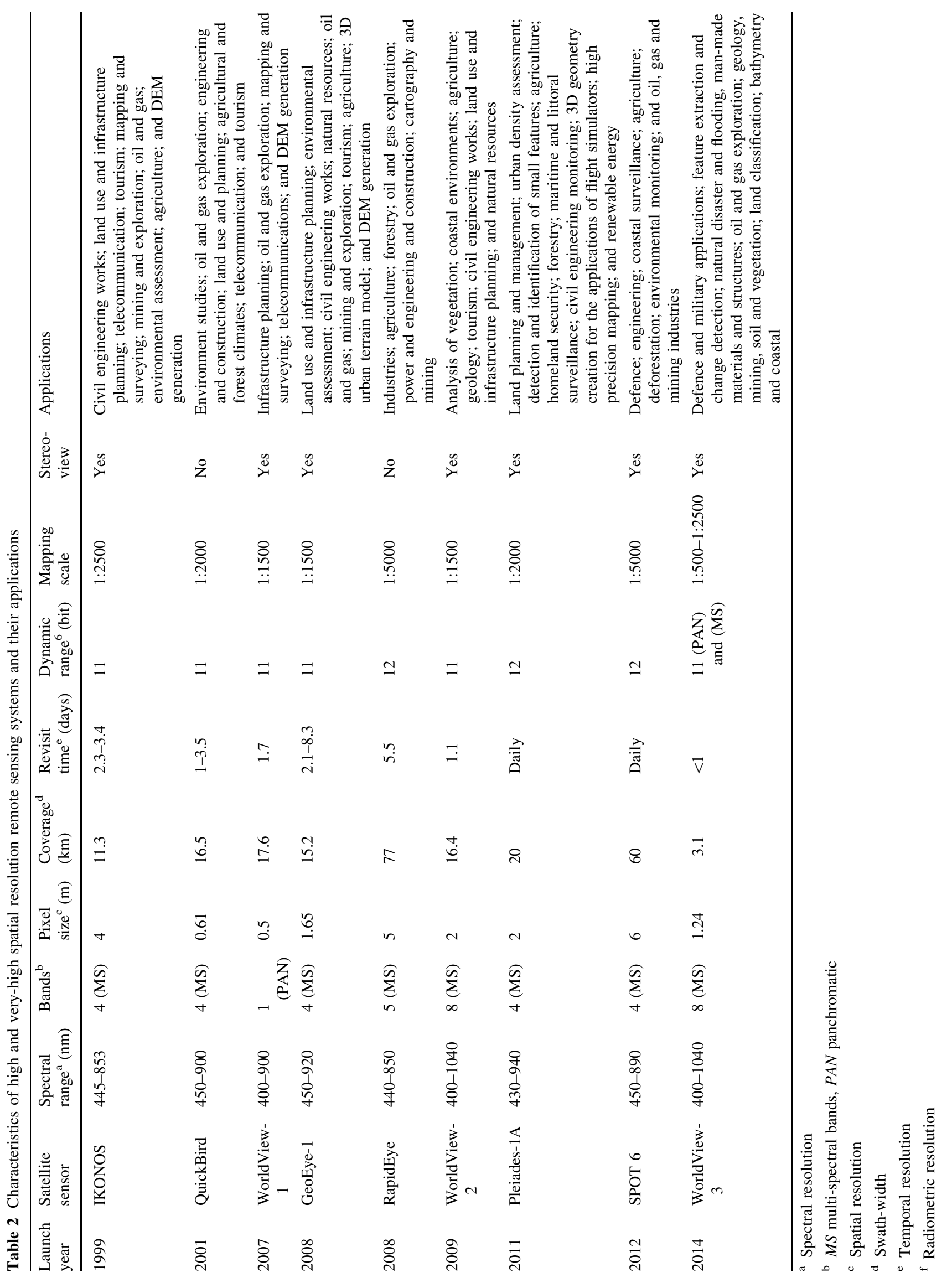


Table 3 Remote sensing and geospatial data resources and providers

\begin{tabular}{|c|c|c|c|c|}
\hline \multirow[t]{3}{*}{ Provider } & \multicolumn{3}{|c|}{ Source and type ${ }^{\mathrm{a}}$} & \multirow[t]{3}{*}{ Comment } \\
\hline & \multicolumn{2}{|c|}{$\begin{array}{l}\text { Non- } \\
\text { commercial }\end{array}$} & \multirow{2}{*}{$\begin{array}{l}\text { Commercial } \\
\mathrm{RS}+\mathrm{G}\end{array}$} & \\
\hline & $\mathrm{RS}$ & G & & \\
\hline $\begin{array}{l}\text { USGS Global Visualisation Viewer (GloVis)—http://glovis. } \\
\text { usgs.gov/ }\end{array}$ & $\boldsymbol{v}$ & & & $\begin{array}{l}\text { Various satellite and land characteristics datasets } \\
\text { including the free Landsat archive }\end{array}$ \\
\hline USGS Earth Explorer-http://earthexplorer.usgs.gov/ & $\boldsymbol{v}$ & & & $\begin{array}{l}\text { Aerial photography, DEM, and various satellite } \\
\text { datasets including the free Landsat archive }\end{array}$ \\
\hline $\begin{array}{l}\text { Global Land-cover Facility (GLCF)—http://glcf.umd.edu/ } \\
\text { data/ }\end{array}$ & $\boldsymbol{v}$ & & & $\begin{array}{l}\text { Various satellite and DEM datasets including the } \\
\text { free Landsat archive }\end{array}$ \\
\hline $\begin{array}{l}\text { USGS LP DAAC Global Data Explorer—http://gdex.cr. } \\
\text { usgs.gov }\end{array}$ & $\boldsymbol{v}$ & $\checkmark$ & & $\begin{array}{l}\text { ASTER Global DEM V2, SRTM, GTOPO30 and } \\
\text { Blue Marble data }\end{array}$ \\
\hline $\begin{array}{l}\text { USGS Earth Resources Observation and Science (EROS) } \\
\text { Centre-https://eros.usgs.gov/find-data }\end{array}$ & $\boldsymbol{v}$ & $\boldsymbol{V}$ & & A collection of data sources \\
\hline Sentinel Data Hub—https://senthub.esa.int & $\boldsymbol{v}$ & & & $\begin{array}{l}\text { Data from the ESA GMES/Copernicus Sentinel } \\
\text { satellites }\end{array}$ \\
\hline $\begin{array}{l}\text { NASA EOSDIS ReverbIECHO—http://reverb.echo.nasa. } \\
\text { gov/ }\end{array}$ & $\boldsymbol{v}$ & $\boldsymbol{v}$ & & $\begin{array}{l}\text { A wide variety of satellite and DEM datasets } \\
\text { including ASTER Global DEM (G-DEM) }\end{array}$ \\
\hline $\begin{array}{l}\text { ESA Landsat } 8 \text { Web Portal—https://landsat8portal.eo.esa. } \\
\text { int }\end{array}$ & $\boldsymbol{v}$ & & & $\begin{array}{l}\text { Landsat } 8 \text { datasets hosted by the European Space } \\
\text { Agency (ESA) }\end{array}$ \\
\hline $\begin{array}{l}\text { Canadian Geospatial Data Infrastructure (CGDI) } \\
\text { GeoGratis_-http://geogratis.gc.ca/ }\end{array}$ & $\boldsymbol{v}$ & $\checkmark$ & & Various RS, DEM and thematic data \\
\hline $\begin{array}{l}\text { Canadian Geospatial Data Infrastructure (CGDI) } \\
\text { GeoConnections Discovery Portal—http://geodiscover. } \\
\text { cgdi.ca/ }\end{array}$ & $\boldsymbol{v}$ & $\checkmark$ & & $\begin{array}{l}\text { Various RS, aerial photography and topographic } \\
\text { data }\end{array}$ \\
\hline $\begin{array}{l}\text { Canadian Council on Geomatics (CCOG) GeoBase_http:// } \\
\text { www.geobase.ca/ }\end{array}$ & $\boldsymbol{v}$ & $\checkmark$ & & DEM, SPOT, Landsat and RADARSAT-1 \\
\hline $\begin{array}{l}\text { Brazil National Institute for Space Research-http://www. } \\
\text { dgi.inpe.br/CDSR/ }\end{array}$ & $\boldsymbol{v}$ & & & CBERS-2 and CBERS-2B \\
\hline $\begin{array}{l}\text { CGIAR-CSI GeoPortal SRTM-http://srtm.csi.cgiar.org/ } \\
\text { SELECTION/inputCoord.asp }\end{array}$ & $\boldsymbol{v}$ & & & $90 \mathrm{~m}$ DEM data \\
\hline $\begin{array}{l}\text { ERSDAC-http://www.jspacesystems.or.jp/ersdac/GDEM/ } \\
\text { E/index.html }\end{array}$ & $\boldsymbol{v}$ & & & $\begin{array}{l}\text { ASTER Global DEM (G-DEM) with } 30 \text { m DEM } \\
\text { data }\end{array}$ \\
\hline $\begin{array}{l}\text { USGS Global Multiresolution Terrain Elevation Data } 2010 \\
\text { (GMTED2010)—http://topotools.cr.usgs.gov/ }\end{array}$ & $\boldsymbol{V}$ & & & Global DEM \\
\hline $\begin{array}{l}\text { USGS National Map Viewer—http://viewer.nationalmap. } \\
\text { gov/ }\end{array}$ & $\boldsymbol{v}$ & $\checkmark$ & & $\begin{array}{l}\text { Orthoimagery, elevation, land-cover, US Topo, } \\
\text { scanned historic topographic maps }\end{array}$ \\
\hline $\begin{array}{l}\text { USDA NRCS Geospatial Data Gateway-http:// } \\
\text { datagateway.nrcs.usda.gov/ }\end{array}$ & $\boldsymbol{v}$ & $\checkmark$ & & Aerial orthoimagery and other geospatial data \\
\hline $\begin{array}{l}\text { Oregon State University HICO—http://hico.coas. } \\
\text { oregonstate.edu/ }\end{array}$ & $\boldsymbol{v}$ & $\checkmark$ & & Hyperspectral imager \\
\hline $\begin{array}{l}\text { USGS EROS Hazards Data Distribution System (HDDS)— } \\
\text { http://hddsexplorer.usgs.gov/ }\end{array}$ & $\boldsymbol{v}$ & & & Hazards related imagery \\
\hline $\begin{array}{l}\text { USGS Land-cover Institute (LCI)—http://landcover.usgs. } \\
\text { gov/landcoverdata.php }\end{array}$ & & $\checkmark$ & & Wide variety of land-cover datasets \\
\hline $\begin{array}{l}\text { Esri ArcGIS Online-http://www.esri.com/software/arcgis/ } \\
\text { arcgisonline/features }\end{array}$ & $\boldsymbol{v}$ & $\checkmark$ & & $\begin{array}{l}\text { A wide variety of raster and vector geospatial } \\
\text { datasets }\end{array}$ \\
\hline $\begin{array}{l}\text { Esri ArcGIS Online Image Services_http://www.arcgis. } \\
\text { com/home/gallery.html }\end{array}$ & $\boldsymbol{v}$ & $\checkmark$ & & $\begin{array}{l}\text { Providing multispectral, temporal, and event } \\
\text { imagery, Basemaps }\end{array}$ \\
\hline GIS Data Depot—http://data.geocomm.com/ & $\boldsymbol{v}$ & $\checkmark$ & & $\begin{array}{l}\text { A wide variety of raster and vector geospatial } \\
\text { datasets }\end{array}$ \\
\hline $\begin{array}{l}\text { Dundee Satellite Receiving Station-http://www.sat. } \\
\text { dundee.ac.uk/ }\end{array}$ & $\boldsymbol{v}$ & & & $\begin{array}{l}\text { Images from NOAA, SeaStar, Terra and Aqua polar } \\
\text { orbiting satellites }\end{array}$ \\
\hline Landmap—http://www.landmap.ac.uk/ & $\boldsymbol{v}$ & $\checkmark$ & & $\begin{array}{l}\text { Providing a combination of remotely sensed imagery } \\
\text { and a high quality spatial data }\end{array}$ \\
\hline
\end{tabular}


Table 3 continued

\begin{tabular}{|c|c|c|c|c|}
\hline \multirow[t]{3}{*}{ Provider } & \multicolumn{3}{|c|}{ Source and type $\mathrm{a}^{\mathrm{a}}$} & \multirow[t]{3}{*}{ Comment } \\
\hline & \multicolumn{2}{|c|}{$\begin{array}{l}\text { Non- } \\
\text { commercial }\end{array}$} & \multirow{2}{*}{$\begin{array}{l}\text { Commercial } \\
\mathrm{RS}+\mathrm{G}\end{array}$} & \\
\hline & $\mathrm{RS}$ & G & & \\
\hline ASTER Spectral Library—http://speclib.jpl.nasa.gov/ & & & & Digital spectral libraries \\
\hline $\begin{array}{l}\text { ASU Thermal Emission Spectroscopy Laboratory Spectral } \\
\text { Library—http://tes.asu.edu/spectral/library/ }\end{array}$ & & & & \\
\hline $\begin{array}{l}\text { USGS View_SPECPR-Software for Plotting Spectra- } \\
\text { http://pubs.usgs.gov/of/2008/1183/ }\end{array}$ & & & & \\
\hline $\begin{array}{l}\text { Reflectance Experiment Laboratory (RELAB) at Brown } \\
\text { University-http://www.planetary.brown.edu/ }\end{array}$ & & & & \\
\hline $\begin{array}{l}\text { AVIRIS (Jet Propulsion Laboratory, Pasadena, CA)—http:// } \\
\text { aviris.jpl.nasa.gov/ }\end{array}$ & $\boldsymbol{V}$ & & & Hyperspectral data \\
\hline Airbus Defence and Space-http://www.astrium-geo.com/ & & & $\checkmark$ & A wide variety of remote sensing data products \\
\hline Alaska Satellite Facility—https://www.asf.alaska.edu/ & & & $\checkmark$ & including SOPT-7 and providing sample imagery \\
\hline Apollo Mapping—https://apollomapping.com/ & & & $\checkmark$ & \\
\hline DigitalGlobe-http://www.digitalglobe.com/ & & & $\checkmark$ & \\
\hline $\begin{array}{l}\text { LAND INFO Worldwide Mapping—http://www.landinfo. } \\
\text { com/ }\end{array}$ & & & $\checkmark$ & \\
\hline MapMart—http://www.mapmart.com & & & $\checkmark$ & \\
\hline $\begin{array}{l}\text { Satellite Imaging Corporation—http://www.satimagingcorp. } \\
\mathrm{com} /\end{array}$ & & & $\checkmark$ & \\
\hline Spatial Energy—http://www.spatialenergy.com/ & & & $\checkmark$ & \\
\hline Penobscot Corporation—http://www.penobscotcorp.com/ & & & $\boldsymbol{V}$ & \\
\hline MDA Geospatial Services_-http://gs.mdacorporation.com/ & & & $\boldsymbol{V}$ & RS, RADARSAT- 1 and RADARSAT- 2 \\
\hline Infoterra-http://terrasar-x-archive.infoterra.de/ & & & $\boldsymbol{V}$ & TerraSAR-X Archive \\
\hline ImageSat International—http://www.imagesatintl.com/ & & & $\boldsymbol{V}$ & EROS A data \\
\hline i-cubed-http://www.i3.com/ & & & $\boldsymbol{V}$ & Various geospatial data \\
\hline German Aerospace Centre-http://www.dlr.de/hr/en/ & & & $\checkmark$ & E-SAR data \\
\hline eMap International—http://www.emap-int.com/ & & & $\boldsymbol{v}$ & Various geospatial data \\
\hline Aero-Graphics-http://www.aero-graphics.com/ & & & $\checkmark$ & Aerial orthoimagery, hyperspectral, LiDAR \& Radar \\
\hline Aerial Services-http://www.aerialservicesinc.com/ & & & $\checkmark$ & \\
\hline
\end{tabular}

${ }^{a} R S$ remote sensing, $G$ geospatial

terms of landscape transformation processes and urban sustainability. Continuous spatial and temporal monitoring is required to evaluate and understand such changes. The capabilities of RS satellites make them a robust and reliable source of data for monitoring the expansion of cities at different spatiotemporal scales [7, 19].

In a recent study, Cockx et al. [12] reported that landcover and land-use information from remote sensing data is a key component in the calibration of many urban growth models. Van de Voorde et al. [81] noted that there is a strong relationship between the change of form in landcover and the functional change in land-use through the analysis of satellite imageries. Classification-based approaches are routinely used to detect the expansion of cities by investigating land-cover and land-use changes $[14,20,50,73,88,92,93,97]$, and the analysis of urban sprawl [8, 26, 30, 32, 47, 96]. A comparison of environmental considerations and critical requirements between optical and non-optical sensors for urban change detection and monitoring the expansion of cities is provided in Fig. 4.

Medium-resolution satellite Landsat imagery has been widely used for urban change detection. Yang and Liu [95] derived urban impervious surfaces to characterise urban spatial growth. Ji et al. [35] characterised the long-term trends and patterns of urban sprawl using multi-stage Landsat Multi-Spectral Scanner (MSS), Thematic Mapper (TM) and Extended Thematic Mapper (ETM+) images based on landscape metrics. Similarly, Du et al. [16] used a time-series of multi-temporal Landsat TM images to derive the overall trend of changes through normalised difference vegetation index (NDVI) based classification. Taubenböck 


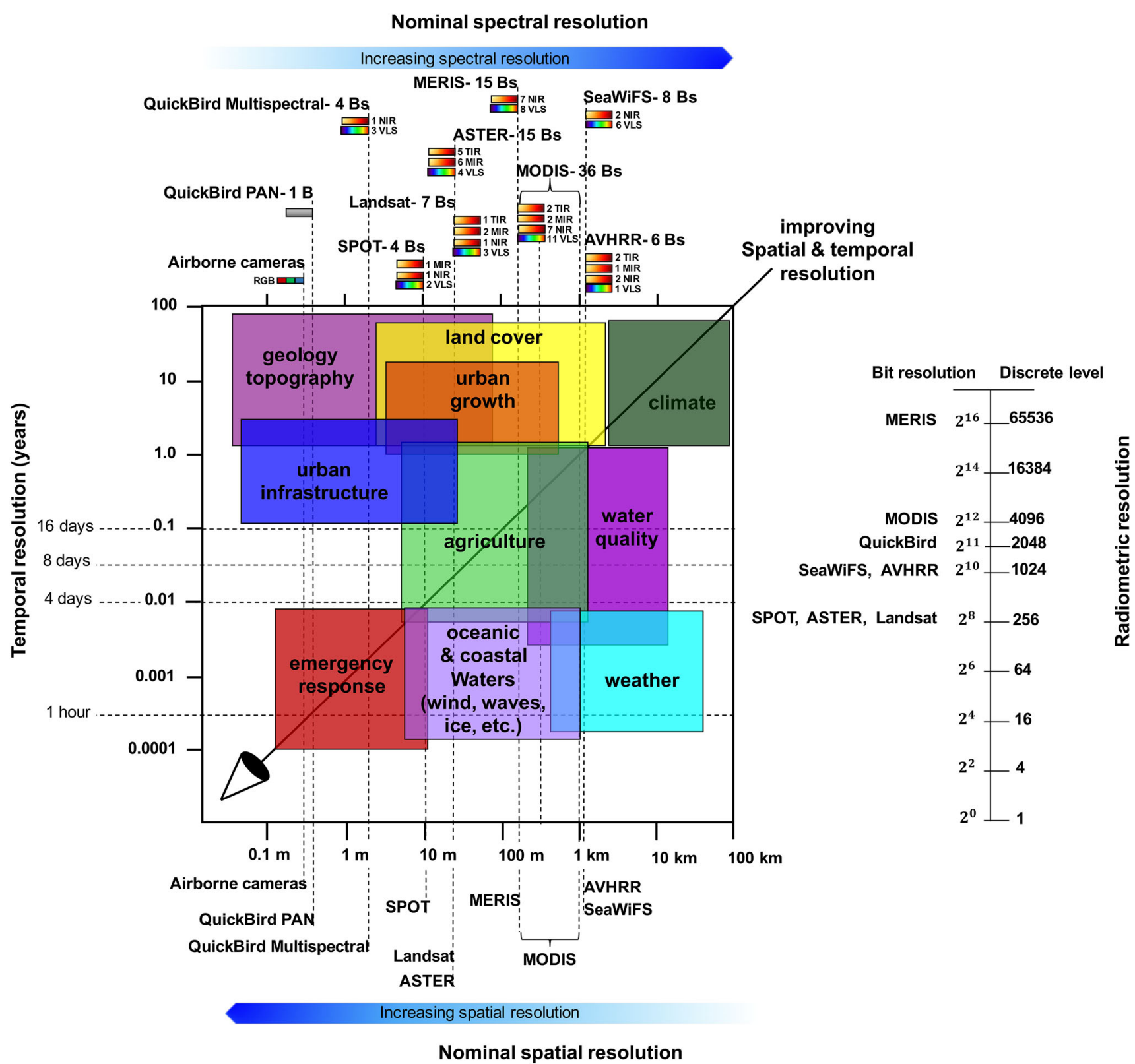

Fig. 3 An overview of spectral, spatial, temporal and radiometric resolution of different optical satellite systems. Spatial and temporal resolution requirements vary widely for monitoring terrestrial, oceanic, and atmospheric features and processes. Each application of remote sensing sensors has its own unique resolution requirements and, thus, there are trade-offs between spatial resolution and

et al. [78] detected temporal and spatial urban sprawl while Abd El-Kawy et al. [1] demonstrated that human activities were responsible for land degradation processes. Pham et al. [65] and Schneider [69] had shown that RS timeseries data can be effectively used to determine long-term trends of urban changes. However, the mapping of some inner city areas for the observation of urban growth or detection of subtle changes is challenging at this level of spatial resolution. coverage, spectral bands and signal-to-noise ratios. Notes and symbols: Bs - the number of spectral bands, which include visible light spectrum (VLS), near-infrared (NIR), mid-infrared (MIR), and thermal infrared (TIR) portion of the electromagnetic spectrum; $\mathrm{RGB}$ - a colour digital image; and $\mathrm{PAN}$ - a panchromatic image Adapted from Jensen [34] and Purkis and Klemas [66]

Satellite images at medium spatial resolution $(10-100 \mathrm{~m})$ cover a large area, often making the urban landscape appear homogeneous, as different attributes of land within one pixel are combined into one. Researchers have, therefore, attempted to fuse multi-source (RS, socioeconomic, vector) data with medium-resolution images to improve the overall resolution, increase model accuracy, and make change detection more perceptible. Jia et al. [36] proposed a method to improve land-cover classification by 


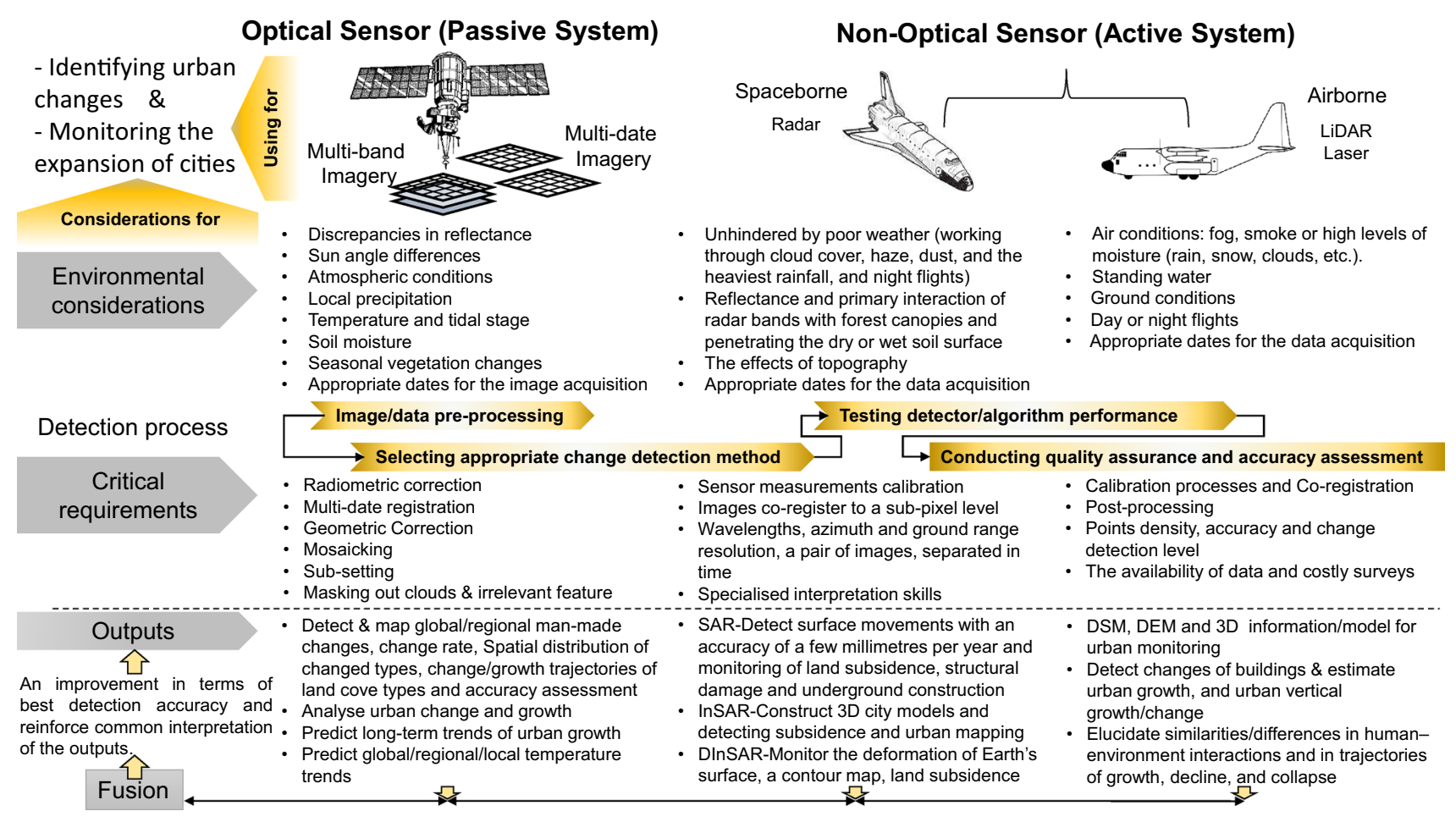

Fig. 4 A comparison of environmental considerations and critical requirements between optical and non-optical sensors for urban change detection and monitoring of the expansion of cities

fusing Landsat 8 Operational Land Imager (OLI) NDVI at $30 \mathrm{~m}$ with MODIS NDVI at $250 \mathrm{~m}$, resulting in a $4 \%$ improvement in the overall classification accuracy, compared to a single temporal Landsat data. On the other hand, Singh et al. [73] showed that the fusion of LiDAR and Landsat data can lead to increased accuracy in distinguishing heterogeneous land-cover over large urban regions. In another study, land-use change was inferred from Landsat ETM+ images integrated with aerial photos and population census data to reveal urban growth and sprawl by Martinuzzi et al. [51]. Change detection of urban land-use from low- and medium-resolution imagery without any improvement by applying other high-resolution RS data or integration with supplementary data, such as census data, is error-prone. The inaccuracy is attributed to mixed pixels that present a spectral mixture from the diverse builtup materials, eventually leading to greater uncertainties in land-cover/land-use classification.

The issue of mixed pixels can be resolved by obtaining more detailed information on urban morphology using high spatial resolution sensors. IKONOS pan-sharpened and SPOT images were combined with different vector maps by Noor and Rosni [61] to analyse the geospatial indicators based on spatial factors. Nassar et al. [59] identified the spatial evolution, urban expansion and growth patterns based on a hybrid classification method and landscape metrics using different datasets to derive suburban classes (e.g. residential, commercial and industrial). Further, Kuffer and Barrosb [45] proposed an approach to monitor unplanned settlements in residential areas by identifying the morphology (size, density, and layout pattern) of urban areas. The mapping of urban land-cover and land-use from high spatial resolution images often faces the issue of spectral variability within one-class and the shadows of buildings and trees that reduce class separability and classification accuracy. Nevertheless, NASA [58] reports that the progression in the RS-based urban area mapping is contributing to the creation of more accurate and detailed maps of cities, enabling an unprecedented understanding of the dynamics of urban growth and sprawl.

\section{Environmental impacts of urban growth}

At a time when informal settlements are emerging as a result of population growth, the likelihood of increasing the occupation of spaces inside and outside cities will be higher, as is the risk of inappropriate urbanisation. The occupation of land as an uncoordinated form is motivated by several factors, namely: limited income of urban dwellers; increased housing demand; the lack of sustainable long-term urban planning; and the insufficiency of legal buildable land. These factors have led to the improper development of cities/urban areas, even in areas considered 
at high risk from natural disasters such as landslide and flooding. The negative effects of the expansion of cities and urban growth are more motivational as a research agenda than the positive ones. One such application is the assessment of the quality of life and socio-economic conditions in urban slums, as for every three city dwellers worldwide one lives in a slum [63]. Many authors applied RS techniques to identify slum locations and classify slums from other land-use types [42-44, 67, 77, 83]. Graesser et al. [23] distinguished the boundaries between formal and informal settlements using an image classification approach. Weeks et al. [89] identified the location of slums and quantified their area using a vegetation-impervious-soil (VIS) model, image texturing, and census data to deduce land-use effects and to produce a slum index map. According to Hagenlocher et al. [24], a clear link between increasing new temporary settlements of population and decreasing natural resources in the vicinity of these settlements was revealed using a time-series of VHR optical satellite imagery.

Other research includes the identification of slum core and its impacts on the environment by Kit et al. [43], and slum area change patterns by Kit and Lüdeke [42]. Despite the progress made in slum detection, there is a need to develop methods that consider the interrelationships between the spatial distribution of slums and socio-economic variables. Moreover, the spatial patterns of slums with the texture of a land-cover type must also be investigated within the urban environment in a consistent manner to improve the understanding of the interrelated land surfaces. In particular, exploiting textural differences between urban land-uses can be beneficial for improving urban mapping with regards to spectral heterogeneity within urban landscapes, as illustrated in Fig. 5, which shows the degree of spatial autocorrelation in the slums (informal) compared to the residential areas (formal). Urban differentiation in terms of similarity and dissimilarity of pixel values within a moving window was assessed using Moran's I in Eq. (1).

$I=\frac{n}{s_{\mathrm{o}}} \frac{\sum_{i=1}^{n} \sum_{j=1}^{n} w_{i, j} z_{i} z_{j}}{\sum_{i=1}^{n} z_{i}^{2}}$

where $z_{i}$ is the deviation of an attribute for feature $i$ from its mean $\left(x_{i}-\bar{X}\right), w_{i, j}$ is spatial weight between features $i$ and $j, n$ is equal to the number of features, and $s_{\mathrm{o}}$ is the aggregate of all the spatial weights in Eq. (2).

$S_{\mathrm{o}}=\sum_{i=1}^{n} \sum_{j=1}^{n} w_{i, j}$

The $z_{i}$-score for the statistic is computed as:

$z_{i}=\frac{I-E[I]}{\sqrt{V[I]}}$

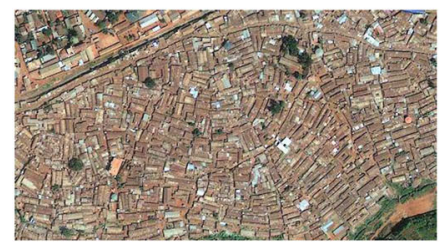

(a)

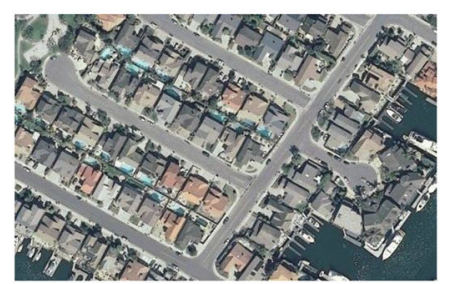

(b)

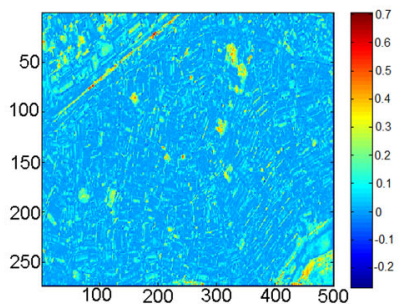

(c)

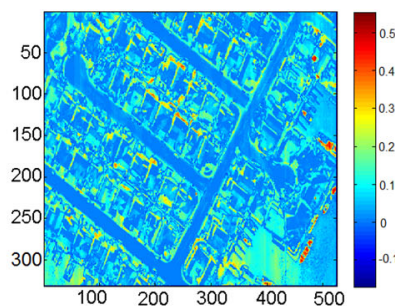

(d)

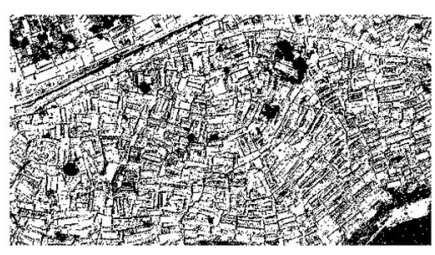

(e)

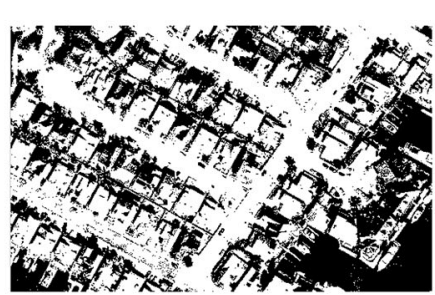

(f)

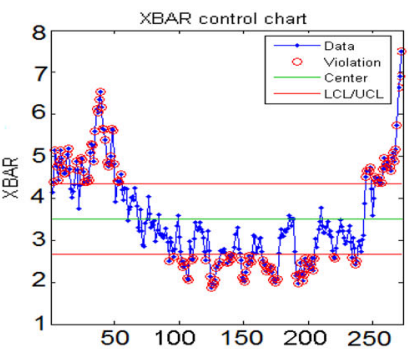

(g)

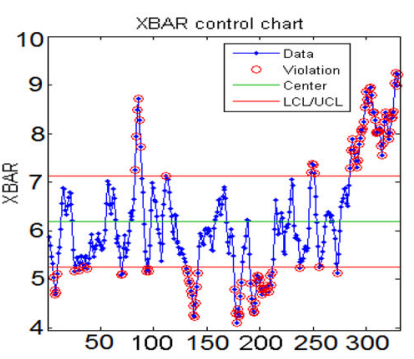

(h)

Fig. 5 Moran's $I$ for high-resolution satellite images using a $3 \times 3$ pixel moving window. a A QuickBird scene of informal residential area (slums). b A GeoEye-1 scene of formal residential area. $\mathbf{c}$ and d Moran's $I$ measuring spatial autocorrelation based on both feature locations and feature values simultaneously. $\mathbf{e}$ and $\mathbf{f}$ The difference in

the texture in the binary form. $\mathbf{g}$ and $\mathbf{h}$ The XBAR control chart of $\mathbf{c}$ and $\mathbf{d}$ to analyse the greatest similarity between the pixel values in each subgroup and the greatest difference between the pixel values in different subgroups 
Fig. 6 Increasing temperature due to increased city size and the number of city dwellers Modified after Bhatta [7]

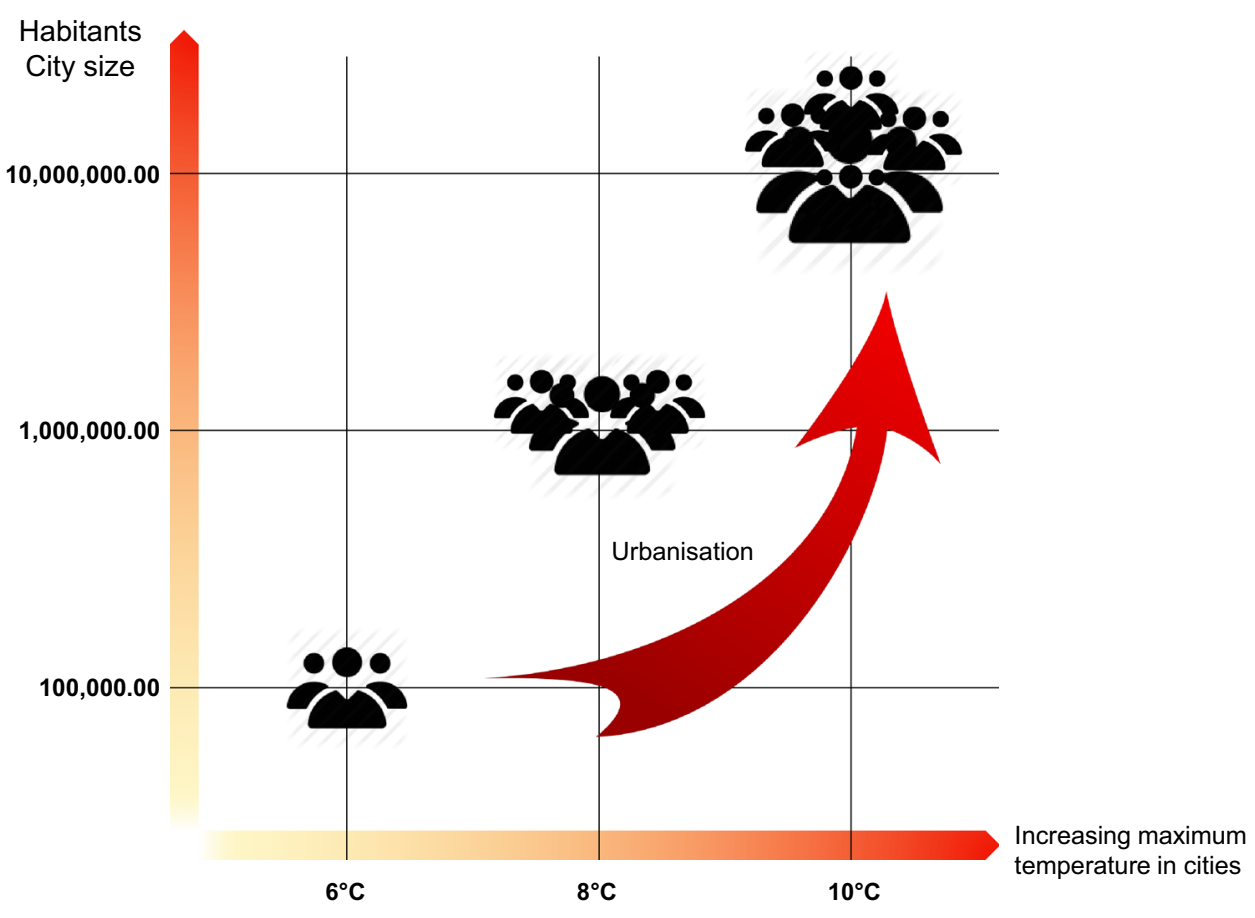

where:

$$
\begin{aligned}
& E[I]=1 /(N-1) \\
& V[I]=E\left[I^{2}\right]-E[I]^{2}
\end{aligned}
$$

Regarding other negative impacts, the increase in city size combined with an increasing number of dwellers cause a corresponding rise in urban air and surface temperatures, known as urban heat island (UHI), as shown in Fig. 6. A positive correlation has been deduced between impervious surfaces and land surface temperature (LST) in the sprawled areas [87, 90], where impervious surface areas become warmer than the surrounding areas. Two main factors cause the UHI effect. First, heat is absorbed from sunlight and subsequently released as thermal infrared radiation by dark surfaces such as pavements, roads and rooftops. The temperature of these surfaces can reach $28-39^{\circ} \mathrm{C}$ higher than the surrounding air [7]. Second, there is a relative lack of vegetation cover in urban areas, especially trees, which work to cool air and balance the components of the environment.

$\mathrm{Li}$ and Yin [48] developed an approach to calculate urban heat island effect ratio (UHIER) that suggests urban areas have relatively higher temperature than the neighbourhoods surrounding the city. Senanayake et al. [70] identified UHIs and the distribution of LST by analysing vegetation cover using NDVI. Le-Xiang et al. [46] assessed the impacts of land-use and land-cover on LST, suggesting around $4.56{ }^{\circ} \mathrm{C}$ higher surface temperature in newly developed urban areas due to decreased vegetation caused by urban expansion.
Several studies have illustrated the use of RS data in analysing air pollution and its quality. Numerical simulations based on satellite data were performed to evaluate the effect of urban sprawl on air quality, surface temperature and their effects on people by De Ridder et al. [15]. In a recent study, Bechle et al. [5] evaluated the extent of the satellite data's ability to resolve urban-scale gradients in ground-level nitrogen dioxide $\left(\mathrm{NO}_{2}\right)$ within a large urban area. Wang et al. [85] derived high resolution aerosol optical thickness (AOT) from Terra-MODIS data by creating four models to analyse the relationship between AOT and PM2.5. Data from the same satellite were used by Nichol et al. [60] to assess 3D air quality over an urban landscape. Sifakis et al. [72] developed an approach to quantify AOT over urban areas by fusing different spectral bands of satellite imageries based on image processing techniques.

With regards to the evaluation of water quality and quantity, Chawira et al. [11] proposed a semi-empirical band ratio model to derive and quantify water quality parameters in two polluted lakes. They also identified the causes of pollution: domestic waste and raw industrial sewage, poor garbage collection, agriculture, and some mining activities, among others. Jay and Guillaume [33] used hyperspectral data for mapping depth and water quality. Trochta et al. [79] presented the identification of water types with different biogeochemical properties and drivers through an optical classification scheme based on RS data. Hunink et al. [27] studied the relationships between groundwater usage and crop type in irrigated 
Table 4 Consequences of expansion of cities against observation variables, impacts, potential and limitations of urban remote sensing applications

\begin{tabular}{|c|c|c|c|}
\hline & \multicolumn{3}{|c|}{ Consequences of the expansion of cities } \\
\hline & Temperature & Air quality & Water quality \\
\hline $\begin{array}{l}\text { Observation variables or } \\
\text { parameters }\end{array}$ & $\begin{array}{l}\text { Dark surfaces (low albedo) } \\
\text { The lack of vegetation }\end{array}$ & $\begin{array}{l}\text { Ozone } \\
\text { Nitrogen dioxide } \\
\text { Sulphur dioxide } \\
\text { PM2.5 and PM10 } \\
\text { Carbon dioxide } \\
\text { Dust aerosol }\end{array}$ & $\begin{array}{l}\text { Turbidity } \\
\text { Total suspended sediment } \\
\text { Volatile suspended solids } \\
\text { Polychlorinated biphenyls } \\
\text { Chlorophyll }\end{array}$ \\
\hline Impacts & $\begin{array}{l}\text { Increased energy } \\
\text { consumption \& cost } \\
\text { Elevated emissions of air } \\
\text { pollutants }\left(\mathrm{SO}_{2}, \mathrm{CO} \text { and }\right. \\
\mathrm{PM}) \text { and greenhouse gases } \\
\left(\mathrm{CO}_{2}\right) \text { - global warming } \\
\text { Compromised human health } \\
\text { and comfort } \\
\text { Impaired water quality }\end{array}$ & $\begin{array}{l}\text { Serious human health problems } \\
\text { Inhibited plant growth } \\
\text { Smog and acid rain } \\
\text { Climate change }\end{array}$ & $\begin{array}{l}\text { Change in colour } \\
\text { More total runoff volume and flooded } \\
\text { land, untreated or poorly treated } \\
\text { sewage } \\
\text { Surface water pollution } \\
\text { Groundwater pollution } \\
\text { Reduced storage capacity, flood control, } \\
\text { light penetration in water- } \\
\text { minimising fish yield } \\
\text { Human health }\end{array}$ \\
\hline Potential & $\begin{array}{l}\text { Observe \& map the surface } \\
\text { urban heat island (SUHI) } \\
\text { Identify the spatial patterns } \\
\text { of upwelling thermal } \\
\text { radiance } \\
\text { Identify urban construction } \\
\text { materials } \\
\text { Time synchronised dense } \\
\text { grid of temperature over a } \\
\text { large area. }\end{array}$ & $\begin{array}{l}\text { Monitor and map the compositions of air } \\
\text { over the globe with high spatial and } \\
\text { temporal coverage } \\
\text { The combination of satellite } \\
\text { observations with ground-based in situ } \\
\text { for monitoring, modelling, simulating } \\
\text { and forecasting the air quality and } \\
\text { climate change } \\
\text { Improve the quantification of air } \\
\text { compositions }\end{array}$ & $\begin{array}{l}\text { Assess surface water, subsurface water, } \\
\text { soil moisture and groundwater with } \\
\text { reasonable accuracy } \\
\text { Assess pollutants spectrally and } \\
\text { suspended sediments using regression } \\
\text { based optical models } \\
\text { Monitoring the vast spatial coverage } \\
\text { and long-term, remotely recognition } \\
\text { concentrations of both sediments \& } \\
\text { chlorophyll and detecting the presence } \\
\text { of water beneath vegetation using the } \\
\text { microwave spectrum }\end{array}$ \\
\hline Limitations/considerations & $\begin{array}{l}\text { Clouds (thermal imageries) } \\
\text { Surface radiative properties } \\
\text { Spectral wavelength }\end{array}$ & $\begin{array}{l}\text { Cloud (the accuracy of air quality } \\
\text { models) } \\
\text { The lower levels of the atmosphere } \\
\text { where exposure to pollution occurs } \\
\text { Chemical and physical measurements } \\
\text { through the atmosphere }\end{array}$ & $\begin{array}{l}\text { Properties of scattering and absorption } \\
\text { of suspended sediments and dissolved } \\
\text { organic matter make it difficult to } \\
\text { determine the intensity of reflected } \\
\text { light } \\
\text { Demand repeated monitoring on short } \\
\text { time-scale } \\
\text { Demand in situ measurements for } \\
\text { calibration the estimation of water } \\
\text { quality } \\
\text { Poor retrieval of water constituents due } \\
\text { to shadows cast on water bodies } \\
\text { Correction for atmospheric influence on } \\
\text { remote sensors is necessary to } \\
\text { differentiate the patterns of water } \\
\text { quality }\end{array}$ \\
\hline
\end{tabular}

areas. The realistic spatial distribution of air and water quality can help to define the urban landscape quality (ULQ). The use of census data alone to quantify ULQ can result in unreliable estimates as census data do not adequately capture the environmental factors such as waterborne diseases and various types of pollution (air, water, toxic chemicals, etc.). Satellite RS data can fill this gap and improve our understanding of the relationships between environmental factors and the urban landscape. Table 4 summarises the potential and shortcomings of remote sensing data for investigating the impacts of urban expansion. 


\section{Sustainable urban environments}

Urban sustainability must be taken into account for planned urban growth to minimise our reliance on natural resources and non-renewable energy. City growth can mitigate the impacts of climate change by minimising ecological footprint, reducing pollution, increasing land-use efficiency, recycling waste, and increasing the use of sustainable materials, and by maximising renewable energy use. In essence, the aim of urban sustainability is to manage resources and to provide services through effective design and implementation of policies, which require access to detailed information on urban indicators. Remote sensing can offer cost-effective solutions for collecting vast amounts of data compared to resource-intensive conventional approaches such as survey and field monitoring. Figure 7 provides an overview of key urban sustainability applications of remote sensing when integrated with the available environmental, economic and social data.

Renewable energy resources in urban areas are highly sensitive to site and surroundings [55] and micro-climate [56], and are dependent on geographical constraints on development and regional economic policies [10]. Remote sensing is particularly suited to the geospatial assessment of the potential of renewable energy technologies (RET) such as wind, solar, wave, biomass and geothermal. Gooding et al. [22] estimated the physical and socio-economic potential for generating electricity from roofmounted PV using digital surface models (DSMs) from LiDAR. Sun et al. [76] developed a regional model of solar
PV generation potential with its economic feasibility using digital elevation model (DEM). LiDAR data was used by Jakubiec and Reinhart [31] to create a map of solar photovoltaic (PV) potential of individual buildings.

Remote sensing can offer cost-effective means of identifying urban surfaces where solar PV can be installed. Kabir et al. [38] used QuickBird scenes to determine bright rooftops of Dhaka for PV applications by applying an object based image analysis (OBIA) approach. Wang and Koch [86] investigated the optimal locations of PV and the base electricity prices resulting from solar energy. Bergamasco and Asinari [6] computed the actual roof surface available for PV installations by classifying roof typologies. Baluyan et al. [4] discriminated rooftops from non-rooftops based on colour/grey level during image segmentation, support vector machine (SVM) classification, and the histogram method.

Jiang et al. [37] analysed the spatiotemporal properties of the wind field using the QuikSCAT satellite data to produce a wind resource map. Walsh-Thomas et al. [84] extended the use of satellite RS data to provide insights into the impacts of large scale wind farms on land surface temperature (LST). An extensive review of the potential of remote sensing techniques in examining geothermal resources was published by Van Der Meer et al. [82]. Ahamed et al. [2] reviewed the biophysical characteristics of biomass for managing energy crops at given sites. Rusu and Onea [68] evaluated wind and wave energy resources along the Caspian Sea. Based on the fused data from multiple satellites, Kaiser and Ahmed [41] derived the spatial distribution of hot springs, lineaments and geothermal localities for RET applications.

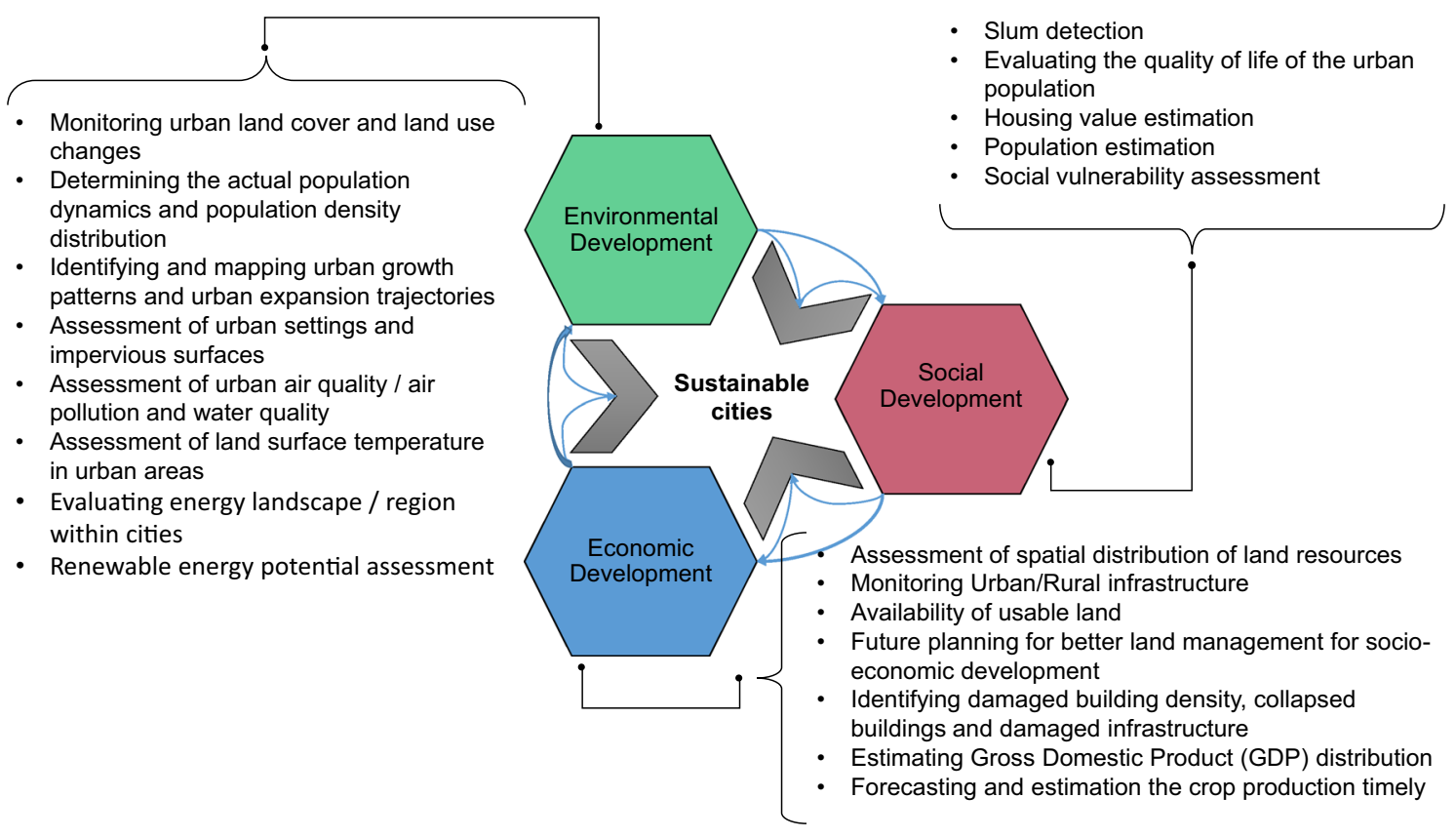

Fig. 7 Key urban sustainability applications of remote sensing 


\section{Trends and future research}

Studies discussed in the previous sections demonstrate the significant potential of remote sensing in the assessment, monitoring and planning for urban sustainability. Figure 8 summarises the reviewed literature on urban growth, sprawl, and land-cover and land-use changes while Fig. 9 summarises previous work on slums, air and water quality, temperature assessment, and renewable energy. In addition, Table 5 presents the state-of-the-art in taxonomy, detection, extraction and pattern recognition in urban applications, focussing on machine learning algorithms such as neural network, decision tree, random forest, etc. The algorithmic aspects of data analysis for various urban applications are also summarised.

In the context of constrained resources, increasing urbanisation, rising vulnerabilities to climate change impacts, and ageing population, cities need to be sustainable, adaptable, smart and resilient [57]. Decisions need to be made based on the contextual evidence of performance of the urban environment, which needs to be collected at a higher resolution in a cost-effective manner. On the other hand, expanding urban areas affect the environment primarily by increasing energy consumption from buildings, transport and industry sectors [66], and by reducing albedo through land-cover change from vegetation to built-up, resulting in increased LST [74]. Both can further reinforce the climate change drivers and act as a positive feedback loop; i.e. increased LST may result in more energy consumption, therefore, more warming, which in turn will result in further increases in LST. The potential of the use of remote sensing in tackling these urban challenges is summarised in Fig. 10.

In Table 6, we present the challenges and/or opportunities in three key research trends: (a) the integration of heterogeneous remote sensing data; (b) algorithms for extracting urban features; and (c) accuracy of urban landcover and land-use classification. We highlighted the main benefits and limitations in each research trend for further investigations in the future.

\section{Discussion and concluding remarks}

We presented a review of the key applications of remote sensing in urban sustainability, and highlighted their potential to address problems associated with the expansion of cities. Nonetheless, there are still challenges and limitations in using remote sensing technology in urban studies. Challenges are related to the remote sensing data

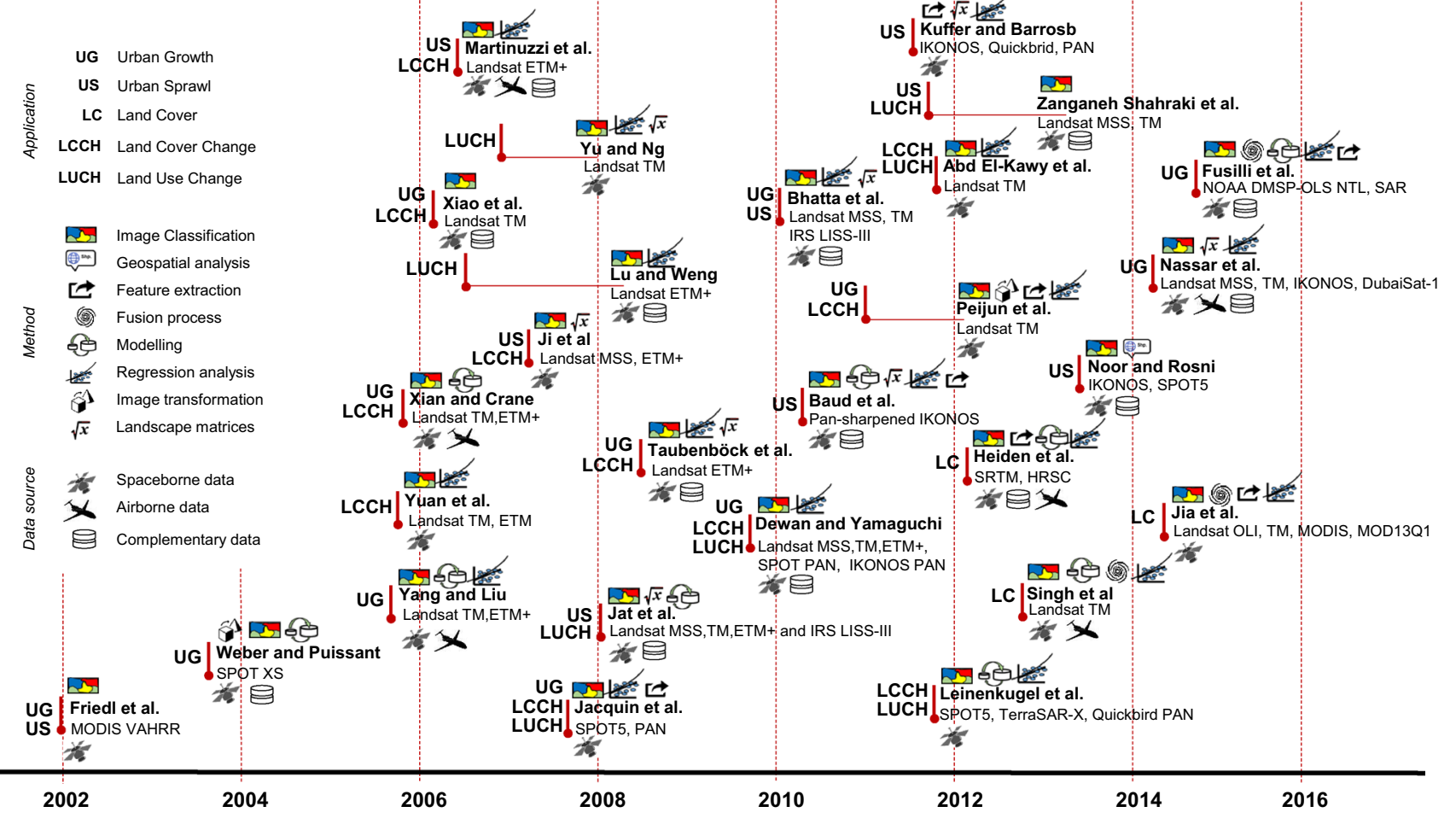

Fig. 8 Previous work on urban growth and sprawl, and land-cover and land-use changes 


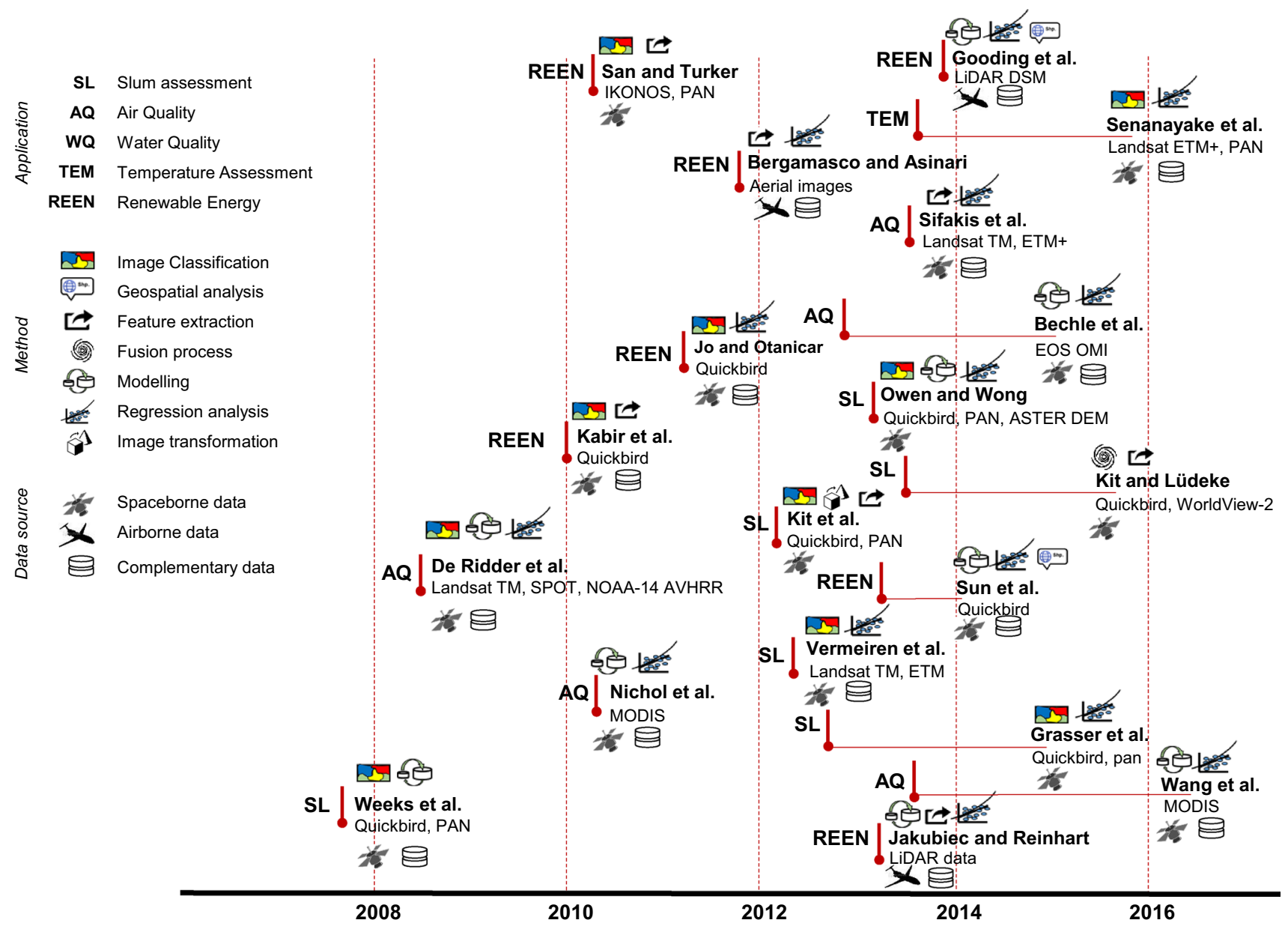

Fig. 9 Previous work on slums, air and water quality, temperature assessment, and renewable energy

itself, as well as its methods of calibration, such as those for dealing with the complex and heterogeneous urban environments. Although the accuracy of the extracted information in RS-based studies has improved, obtaining an accurate thematic map from RS-based classifications remains a challenge, due to: (a) the complexity of the urban landscape; (b) limitations of selected computer vision and image processing techniques; and (c) the complexities and nuances in integrating or fusing multi-source data. Spectral uncertainty still exists between the separated classes of the urban land-cover and land-use, such as bare soil and/or dry mud with impervious surfaces. Furthermore, the concentration of diverse built-up materials in a small area results in pixel generalisation, eventually leading to classification errors, which can be particularly problematic when working with low-resolution images.

The key advantage of remote sensing technology arises from the capability to integrate data from multiple sensors with similar or dissimilar spatial, spectral, or temporal resolutions to collate information on a common theme. However, there is a need for robust algorithms for fully automating the registration of data captured with many sensors, such as optical and radar, hyperspectral imagery and LiDAR data, which operate at disparate resolutions and use diverse acquisition approaches. Although the derived information from such sensors are potentially very useful for urban sustainability assessment, fusing their data is a real challenge using the conventional approaches of data processing. Additionally, techniques for object recognition, classification, segmentation, and change detection from the outputs of data fusion are still in their infancy. Therefore, to take full advantage of the diversity of remote sensing data within the urban environment, there is a need to develop new strategies and further refine existing techniques and approaches. 
Table 5 The state-of-the-art in taxonomy, detection, extraction and pattern recognition in urban applications

\begin{tabular}{lllll}
\hline Application & $\begin{array}{l}\text { Taxonomy/ } \\
\text { quantification } \\
\text { algorithms }\end{array}$ & Lerits & Example \\
& & & \\
\end{tabular}

\begin{tabular}{ll}
\hline $\begin{array}{l}\text { Seismic building structural } \\
\text { types (SBSTs) }\end{array}$ & $\begin{array}{c}\text { Support vector } \\
\text { machine (SVM) and } \\
\text { random forest (RF) }\end{array}$ \\
\\
\\
$\begin{array}{ll}\text { Urban change detection: } & \text { Scene classification } \\
\text { land-use transitions } & \text { with a bag-of- } \\
& \text { visual-words } \\
\text { (BOVW) }\end{array}$
\end{tabular}

Urban land-cover and landuse classification

Monitoring changes in impervious surfaces

Change detection

Water quality, and sustainable water resources management

Binary tree SVM based on JM distance

\section{MRGU}

Unsupervised Neural network and feature transformation

Integrated data fusion and mining (IDFM) and artificial neural
Classify the combination of different remote sensing data

Derive sets of valuable features to characterise the urban environment

Model an effective earthquake loss and spatial distribution

ABTSVM classifier outperforms other multi-class SVM classifiers

Obtain semantic scene classes

Effectively analyse land-use changes

Satisfactory accuracy

Improve classification accuracy.

Classify hyperspectral images adequately

Ease of interpretation of urban classes

Integrate multiple endmember spectral mixture analysis (MESMA), analysis of regression residuals, spatial statistics (Getis Ord) with Moran's I, and urban growth theories in an effective manner

Quantify and identify the magnitude of impervious surface changes and their spatial distribution.

Deep architecture (SDAE) for better representation of the relationships between feature- and pixel-pair

Mapping based FCA and function learning to highlight change in a robust manner

Denoising autoencoder network (ANN)
Hierarchical supervised classification scheme has uncertainties in separating SBSTs

Performance depends on the ranked features

Accuracy is subject to the addition of further features and subset based categories

Time-consuming

Very difficult to achieve the direct selection of the "from-to" samples from the dataset

Classification performance in certain cases is negatively affected by the redundancy of information

Confusion between road and bare soil classes

Instability and complexity in the structure and parameters of the binary tree SVM

Not universally applicable due to specific behaviour of maximum noise fraction (MNF)

Difficult to use for quantifying changes in urban centres

Performance (regression residuals) is subject to the structure of urban regions

Uncertainty in the featurepair

High computational cost

Complexity structures of stacked denoising autoencoders (SDAE)

Many constraints are required to extract useful features

Prediction accuracy may be Imen et al. [28] effected by uncertainties in the fused data

A large number of variables is required to overcome the uncertainty

Not applicable for regional meteorology parameters
Shahtahmassebi et al. [71]

Zhang et al. [99]$$
\text { (7) }[71]
$$

Wu et al. [91]

Du et al. [17]

Geiß et al. [21]
A near real-time monitoring and the Efficiency

Forecasting reliability

Potential for local adoption 
Table 5 continued

\begin{tabular}{|c|c|c|c|c|}
\hline Application & $\begin{array}{l}\text { Taxonomy/ } \\
\text { quantification } \\
\text { algorithms }\end{array}$ & Merits & Limitations & Example \\
\hline Air temperature estimation & SVM & $\begin{array}{l}\text { Fully automated method } \\
\text { SVM regression is robust } \\
\text { Regression errors can be modelled at } \\
\text { the pixel level, improving accuracy } \\
\text { estimation }\end{array}$ & $\begin{array}{l}\text { Requires expert users to } \\
\text { apply SVM } \\
\text { Does not work well under } \\
\text { non cloud-free conditions } \\
\text { and require in situ } \\
\text { measurements } \\
\text { Regression error } \\
\text { distribution is insufficient }\end{array}$ & Moser et al. [54] \\
\hline $\begin{array}{l}\text { Fine-scale population } \\
\text { estimation for urban } \\
\text { management, emergency } \\
\text { response and } \\
\text { epidemiological }\end{array}$ & $\begin{array}{l}\mathrm{RF} \text { and } \\
\text { Linear regression } \\
\text { modelling }\end{array}$ & $\begin{array}{l}\text { Able to classify building types and } \\
\text { extract their footprints in the } \\
\text { heterogeneous urban areas } \\
\text { Improved classification accuracy } \\
\text { Ease of adoption }\end{array}$ & $\begin{array}{l}\text { Subject to the accuracy of } \\
\text { the selected morphology } \\
\text { filter } \\
\text { Use of large numbers of } \\
\text { metrics and variables for } \\
\text { building type } \\
\text { classification } \\
\text { Building background } \\
\text { metrics do not show its } \\
\text { advantage in the block } \\
\text { classification } \\
\text { Classification uncertainty } \\
\text { for non-residential } \\
\text { buildings }\end{array}$ & Xie et al. [94] \\
\hline $\begin{array}{l}\text { Renewable energy and } \\
\text { urban feature extraction }\end{array}$ & $\begin{array}{l}\text { Shadow detection and } \\
\text { building geometry } \\
\text { identification }\end{array}$ & $\begin{array}{l}\text { Easy to apply } \\
\text { Sufficient to generate 3D model of } \\
\text { urban buildings } \\
\text { Reliable analysis of the solar energy } \\
\text { potential } \\
\text { Identify the availability of 3D surfaces } \\
\text { Flexibility and feasibility }\end{array}$ & $\begin{array}{l}\text { Not fully automated } \\
\text { Not suitable for dense } \\
\text { urban areas } \\
\text { Sensitive to the quality of } \\
\text { satellite images }\end{array}$ & $\begin{array}{l}\text { Kadhim et al. } \\
{[39,40]}\end{array}$ \\
\hline $\begin{array}{l}\text { Impervious surfaces } \\
\text { estimation }\end{array}$ & SVM and RF & $\begin{array}{l}\text { Increased classification accuracy } \\
\text { Does not depend on combinations of } \\
\text { features } \\
\text { Data can be fused to optimise } \\
\text { parameters efficiently } \\
\text { Ease of application }\end{array}$ & $\begin{array}{l}\text { Needs many texture } \\
\text { matrices } \\
\text { Inability to handle the } \\
\text { confusion in shaded areas } \\
\text { and bare soil } \\
\text { Over-fitting }\end{array}$ & $\begin{array}{l}\text { Zhang and Lin } \\
\text { [98] }\end{array}$ \\
\hline
\end{tabular}

Apart from the challenges in the assimilation and integration of data, the methods and algorithms for extracting features and related information need to be considered for observing city growth and its environmental impacts. Some of these challenges relate to the information extraction from image texture; inference of contextual and semantic information using computer vision techniques; extraction of the geometric attributes of urban features such as 3D objects, and the enhancement of the degree of automation in accelerating the deduction of useful information from satellite images.
One of the goals of our research is to highlight the potential of remote sensing for tackling emerging environmental issues in countries without the vast environmental and land monitoring infrastructure typically found in Europe and the west. Countries and regions on the northern and southern shores of the Mediterranean are characterised by rapid urbanisation and environmental degradation, but are not well presented in the literature in terms of the development and applications of urban sustainability. The concern is that the region has experienced significant environmental changes in the past, and is 
Fig. 10 The hypothetical deterioration of environmental systems and the potential of the use of remote sensing in their restoration Modified after Purkis and Klemas [66]

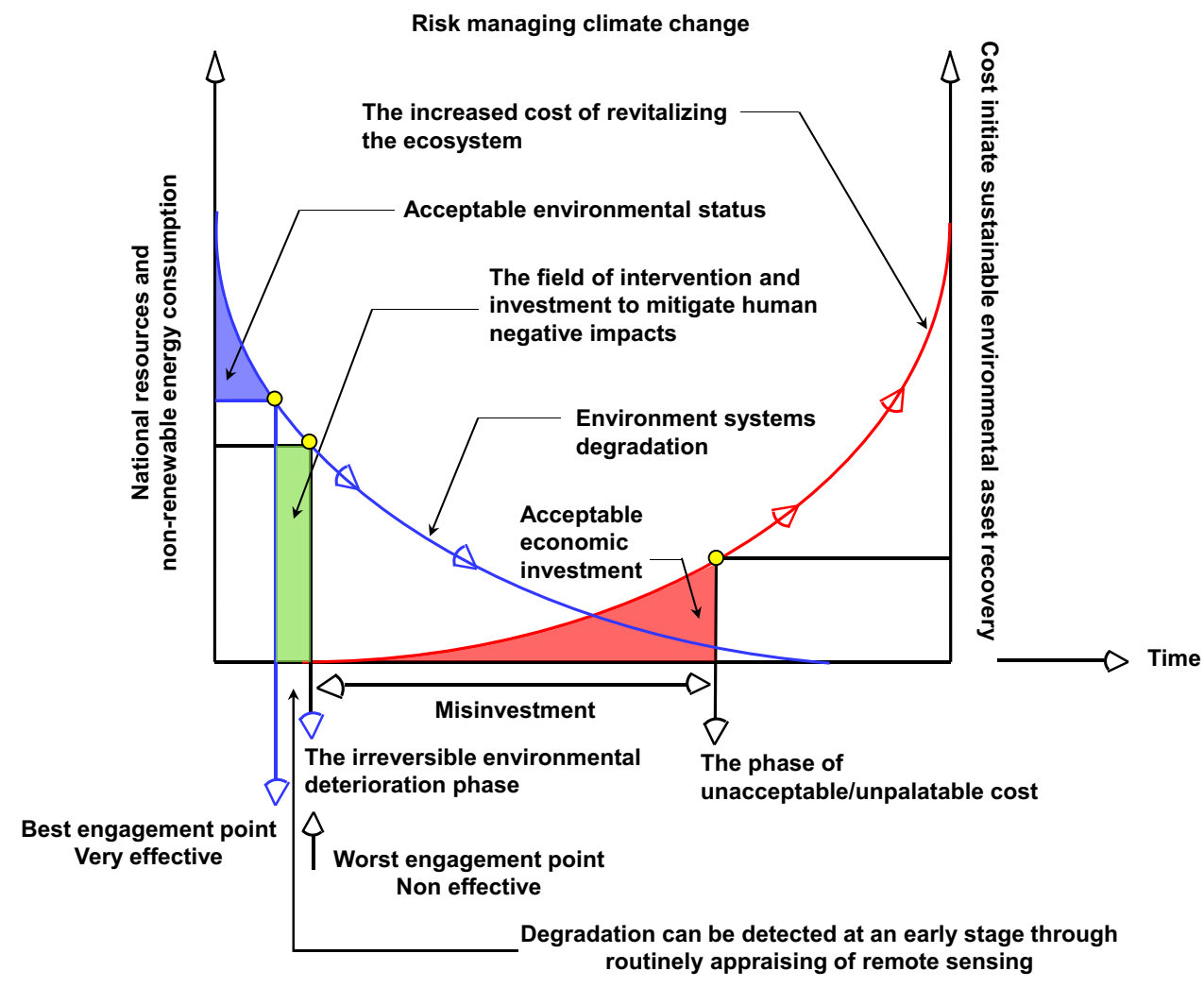

Table 6 Directions of future research

\begin{tabular}{lll}
\hline Integration of heterogeneous data & Algorithms to identify urban features & $\begin{array}{l}\text { Improve accuracy for spectral } \\
\text { classification algorithms }\end{array}$
\end{tabular}

Objective Improve the spatial and spectral resolution Improve the classification accuracy

Enhance the ability of features detection and display

Promote the geometric precision

Increase the capability of the change detection

Refine, replace or repair the defect of image data

Handle multi-source remote sensing data at the pixel, feature and decision of level fusion

Problems requiring solutions

A rescaling of multisource data of divers EO instruments

Assessing the distortion of the spatial and spectral resolution

Time-consuming and subjective

The complexity and/or availability of a large training datasets for the deep learning features

Manual or semi-automated the post-processing process

Computation efficiency and effectiveness

The quality of the distinguishing features

With the fusion schemes, the optimal combining strategy of the current fusion algorithms is a challenging task and promising research that requires further investigations in the near future
Accelerate future processing and improve classification accuracy

Automated processes for detecting, extracting, simulating, classifying and modelling urban features

Capability of handling and fusing the large number of datasets

Improve image objects segmentation

Increase the reliability and precision of the feature extraction

Mitigate the ambiguous and uncertainty

Further developments for fusing LiDAR data with thermal, multispectral and hyperspectral imagery

Reliable determination of the boundaries of urban objects in an automated manner

Further improvements for addressing different characteristics of EO data

Ability to cope with unpredictable environmental and illumination factors of diverse datasets

Similarity in the characteristics of spectral, textural and geometrical-based between the urban objects and their background

The problems in the occlusions and relief distortions

Computational time to perform a task
Capability of separating urban landcover and land-use classes in an adequate manner.

For a better visualisation and interpretation of urban landscape

Performing a change detection analysis and pattern recognition

Accurately characterise the model parameters for different urban remote sensing applications

\section{Mixed pixels}

Uncertainty in the urban land-cover and land-use classes

Mixed objects

Promote pixel-based and object-based classification using contextual information

Over-fitting can cause speckled results that are difficult to interpret

An automatic labelling strategy is required for actual label sets in several applications

Further refinements for the fusion of diverse data sources

Integrate the derived urban features (e.g. building shadows) and/or spatial matrices with various classifier schemes

Investigate the recent computer vision techniques for improving the accuracy 
projected to be exposed to significant risks from climate change and increasing human impacts to its natural resources and ecosystems. Reviews on advances in remote sensing presented here are envisaged to encourage further adoption in urban sustainability applications, in particular in the countries and regions most affected by global environmental change.

Acknowledgments This research has been funded by a grant from the Higher Committee of Education Development (HCED) in Iraq. The authors gratefully acknowledge the grant support by HCED for achieving this work. The authors would also like to thank $\mathrm{Mr}$ Mohammed Salih and Mrs Amera Ali for a useful discussion on the applications of urban remote sensing. The authors are thankful to three anonymous reviewers and the associate editor for their helpful comments.

\section{Compliance with ethical standards}

Conflict of interest The authors declare that they have no conflict of interest.

Open Access This article is distributed under the terms of the Creative Commons Attribution 4.0 International License (http://creative commons.org/licenses/by/4.0/), which permits unrestricted use, distribution, and reproduction in any medium, provided you give appropriate credit to the original author(s) and the source, provide a link to the Creative Commons license, and indicate if changes were made.

\section{References}

1. Abd El-Kawy OR et al (2011) Land use and land cover change detection in the western Nile delta of Egypt using remote sensing data. Appl Geogr 31(2):483-494

2. Ahamed T et al (2011) A review of remote sensing methods for biomass feedstock production. Biomass Bioenergy 35(7):2455-2469

3. Ameen RFM et al (2015) A critical review of environmental assessment tools for sustainable urban design. Environ Impact Assess Rev 55:110-125

4. Baluyan $\mathrm{H}$ et al (2013) Novel approach for rooftop detection using support vector machine. ISRN Machine Vision, Egypt

5. Bechle MJ et al (2013) Remote sensing of exposure to NO 2: satellite versus ground-based measurement in a large urban area. Atmos Environ 69:345-353

6. Bergamasco L, Asinari P (2011) Scalable methodology for the photovoltaic solar energy potential assessment based on available roof surface area: further improvements by ortho-image analysis and application to Turin (Italy). Sol Energy 85(11):2741-2756

7. Bhatta B (2010) Analysis of urban growth and sprawl from remote sensing data. Springer, New York

8. Bhatta B et al (2010) Quantifying the degree-of-freedom, degreeof-sprawl, and degree-of-goodness of urban growth from remote sensing data. Appl Geogr 30(1):96-111

9. Bhatta B et al (2010) Urban sprawl measurement from remote sensing data. Appl Geogr 30(4):731-740

10. Calvert $\mathrm{K}$ et al (2013) Toward renewable energy geo-information infrastructures: applications of GIScience and remote sensing that build institutional capacity. Renew Sustain Energy Rev 18:416-429

11. Chawira $M$ et al (2013) Remote sensing based water quality monitoring in Chivero and Manyame lakes of Zimbabwe. Phys Chem Earth Parts A/B/C 66:38-44
12. Cockx K et al (2014) Quantifying uncertainty in remote sensingbased urban land-use mapping. Int J Appl Earth Obs Geoinf 31:154-166

13. Curran PJ (1985) Principles of remote sensing. Longman Inc, London

14. Dewan AM, Yamaguchi Y (2009) Land use and land cover change in Greater Dhaka, Bangladesh: using remote sensing to promote sustainable urbanization. Appl Geogr 29(3):390-401

15. De Ridder K et al (2008) Simulating the impact of urban sprawl on air quality and population exposure in the German Ruhr area. Part II: Development and evaluation of an urban growth scenario. Atmos Environ 42(30):7070-7077

16. Du P et al (2010) Monitoring urban land cover and vegetation change by multi-temporal remote sensing information. Min Sci Technol (China) 20(6):922-932

17. Du P et al (2012) A novel binary tree support vector machine for hyperspectral remote sensing image classification. Opt Commun 285(13-14):3054-3060

18. Easterlin RA et al (2011) The impact of modern economic growth on urban-rural differences in subjective well-being. World Dev 39(12):2187-2198

19. Friedl MA et al (2002) Global land cover mapping from MODIS: algorithms and early results. Remote Sens Environ 83(1-2):287-302

20. Fusilli L et al (2014) Urban growth assessment around Winam Gulf of Kenya based on satellite imagery. Acta Astronaut 93:279-290

21. Geiß C et al (2015) Estimation of seismic building structural types using multi-sensor remote sensing and machine learning techniques. ISPRS J Photogr Remote Sens 104:175-188

22. Gooding J et al (2013) Solar city indicator: a methodology to predict city level PV installed capacity by combining physical capacity and socio-economic factors. Sol Energy 95:325-335

23. Graesser $\mathbf{J}$ et al (2012) Image based characterization of formal and informal neighborhoods in an urban landscape. IEEE J Sel Top Appl Earth Obs Remote Sens 5(4):1164-1176

24. Hagenlocher $M$ et al (2012) Integrated assessment of the environmental impact of an IDP camp in Sudan based on very high resolution multi-temporal satellite imagery. Remote Sens Environ 126:27-38

25. Hamidi S, Ewing R (2014) A longitudinal study of changes in urban sprawl between 2000 and 2010 in the United States. Landsc Urban Plan 128:72-82

26. Heiden U et al (2012) Urban structure type characterization using hyperspectral remote sensing and height information. Landsc Urban Plan 105(4):361-375

27. Hunink JE et al (2015) Estimating groundwater use patterns of perennial and seasonal crops in a Mediterranean irrigation scheme, using remote sensing. Agric Water Manag 162:47-56

28. Imen $\mathrm{S}$ et al (2015) Developing the remote sensing-based early warning system for monitoring TSS concentrations in Lake Mead. J Environ Manag 160:73-89

29. Jackson LE (2003) The relationship of urban design to human health and condition. Landsc Urban Plan 64(4):191-200

30. Jacquin A et al (2008) A hybrid object-based classification approach for mapping urban sprawl in periurban environment. Landsc Urban Plan 84(2):152-165

31. Jakubiec JA, Reinhart CF (2013) A method for predicting citywide electricity gains from photovoltaic panels based on LiDAR and GIS data combined with hourly Daysim simulations. Sol Energy 93:127-143

32. Jat MK et al (2008) Monitoring and modelling of urban sprawl using remote sensing and GIS techniques. Int J Appl Earth Obs Geoinf 10(1):26-43

33. Jay S, Guillaume M (2014) A novel maximum likelihood based method for mapping depth and water quality from hyperspectral remote-sensing data. Remote Sens Environ 147:121-132 
34. Jensen JR (2009) Remote sensing of the environment: an earth resource perspective 2/e. Pearson Education, India

35. Ji W et al (2006) Characterizing urban sprawl using multi-stage remote sensing images and landscape metrics. Comput Environ Urban Syst 30(6):861-879

36. Jia K et al (2014) Land cover classification of finer resolution remote sensing data integrating temporal features from time series coarser resolution data. ISPRS J Photogr Remote Sens 93:49-55

37. Jiang D et al (2013) Evaluating the spatio-temporal variation of China's offshore wind resources based on remotely sensed wind field data. Renew Sustain Energy Rev 24:142-148

38. Kabir MH et al (2010) Calculation of bright roof-tops for solar PV applications in Dhaka Megacity, Bangladesh. Renew Energy 35(8):1760-1764

39. Kadhim NMM et al (2015) Automatic extraction of urban structures based on shadow information satellite imagery. In: 14th conference of international building performance simulation association (building simulation 2015), 7-9 Dec 2015. Hyderabad, pp 2607-2614

40. Kadhim NMSM et al (2015) Shadow detection from very high resolution satellite image using grabcut segmentation and ratioband algorithms. Int Archiv Photogr Remote Sens Spat Inf Sci 40(suppl W2 XL.3):95-101. doi:10.5194/isprsarchives-XL-3W2-95-2015

41. Kaiser MF, Ahmed S (2013) Optimal thermal water locations along the Gulf of Suez coastal zones, Egypt. Renew Energy $55: 374-379$

42. Kit O, Lüdeke M (2013) Automated detection of slum area change in Hyderabad, India using multitemporal satellite imagery. ISPRS J Photogr Remote Sens 83:130-137

43. Kit $\mathrm{O}$ et al (2012) Texture-based identification of urban slums in Hyderabad, India using remote sensing data. Appl Geogr 32(2):660-667

44. Kohli D et al (2012) An ontology of slums for image-based classification. Comput Environ Urban Syst 36(2):154-163

45. Kuffer M, Barrosb J (2011) Urban morphology of unplanned settlements: the use of spatial metrics in VHR remotely sensed images. Proc Environ Sci 7:152-157

46. Le-Xiang Q et al (2006) Impacts of land use and cover change on land surface temperature in the Zhujiang Delta. Pedosphere 16(6):681-689

47. Leinenkugel $\mathrm{P}$ et al (2011) Settlement detection and impervious surface estimation in the Mekong Delta using optical and SAR remote sensing data. Remote Sens Environ 115(12):3007-3019

48. Li C-F, Yin J-Y (2013) A study on urban thermal field of Shanghai using multi-source remote sensing data. J Indian Soc Remote Sens 41(4):1009-1019

49. Longley PA (2002) Geographical information systems: will developments in urban remote sensing and GIS lead to 'better' urban geography? Progr Hum Geogr 26(2):231-239

50. Lu D, Weng Q (2006) Use of impervious surface in urban landuse classification. Remote Sens Environ 102(1-2):146-160

51. Martinuzzi S et al (2007) Land development, land use, and urban sprawl in Puerto Rico integrating remote sensing and population census data. Landsc Urban Plan 79(3-4):288-297

52. Masek JG et al (2000) Dynamics of urban growth in the Washington DC metropolitan area, 1973-1996, from Landsat observations. Int J Remote Sens 21(18):3473-3486

53. Merbitz $\mathrm{H}$ et al (2012) GIS-based identification of spatial variables enhancing heat and poor air quality in urban areas. Appl Geogr 33:94-106

54. Moser G et al (2015) Estimation of air surface temperature from remote sensing images and pixelwise modeling of the estimation uncertainty through support vector machines. IEEE J Sel Top Appl Earth Obs Remote Sens 8(1):332-349
55. Mourshed M et al (2015) Smart grid futures: perspectives on the integration of energy and ICT services. Energy Proc 75:1132-1137

56. Mourshed M (2016) Climatic parameters for building energy applications: a temporal-geospatial assessment of temperature indicators. Renew Energy 94:55-71

57. Mourshed M et al (2016) SMART: a process-oriented methodology for resilient smart cities. In: 2016 IEEE international smart cities conference (ISC2), Trento, 12-15 September 2016

58. NASA (2001) Satellite maps provide better urban sprawl insight. NASA, USA

59. Nassar AK et al (2014) Developing the desert: the pace and process of urban growth in Dubai. Comput Environ Urban Syst 45:50-62

60. Nichol JE et al (2010) A 3D aerosol and visibility information system for urban areas using remote sensing and GIS. Atmos Environ 44(21):2501-2506

61. Noor NM, Rosni NA (2013) Determination of spatial factors in measuring urban sprawl in Kuantan using remote sensing and GIS. Proc Soc Behav Sci 85:502-512

62. Ok AO (2013) Automated detection of buildings from single VHR multispectral images using shadow information and graph cuts. ISPRS J Photogr Remote Sens 86:21-40

63. Owen KK, Wong DW (2013) An approach to differentiate informal settlements using spectral, texture, geomorphology and road accessibility metrics. Appl Geogr 38:107-118

64. Patino JE, Duque JC (2013) A review of regional science applications of satellite remote sensing in urban settings. Comput Environ Urban Syst 37:1-17

65. Pham HM et al (2011) A case study on the relation between city planning and urban growth using remote sensing and spatial metrics. Landsc Urban Plan 100(3):223-230

66. Purkis SJ, Klemas VV (2011) Remote sensing and global environmental change. Wiley, New York

67. Rhinane $\mathrm{H}$ et al (2011) Detecting slums from SPOT data in Casablanca Morocco using an object based approach. J Geogr Inf Syst 3(3):217

68. Rusu E, Onea F (2013) Evaluation of the wind and wave energy along the Caspian Sea. Energy 50:1-14

69. Schneider A (2012) Monitoring land cover change in urban and peri-urban areas using dense time stacks of Landsat satellite data and a data mining approach. Remote Sens Environ 124:689-704

70. Senanayake I et al (2013) Remote sensing based analysis of urban heat islands with vegetation cover in Colombo city, Sri Lanka using Landsat-7 ETM+ data. Urban Clim 5:19-35

71. Shahtahmassebi AR et al (2016) Remote sensing of impervious surface growth: a framework for quantifying urban expansion and redensification mechanisms. Int J Appl Earth Obs Geoinf 46:94-112

72. Sifakis NI et al (2014) CHRISTINE Code for High ResolutIon Satellite mapping of optical ThIckness and ÅNgstrom Exponent. Part II: first application to the urban area of Athens, Greece and comparison to results from previous contrast-reduction codes. Comput Geosci 62:142-149

73. Singh KK et al (2012) LiDAR-Landsat data fusion for large-area assessment of urban land cover: balancing spatial resolution, data volume and mapping accuracy. ISPRS J Photogr Remote Sens $74: 110-121$

74. Stone B, Norman JM (2006) Land use planning and surface heat island formation: a parcel-based radiation flux approach. Atmos Environ 40(19):3561-3573

75. Sun C et al (2013) Quantifying different types of urban growth and the change dynamic in Guangzhou using multi-temporal remote sensing data. Int J Appl Earth Obs Geoinf 21:409-417

76. Sun Y-W et al (2013) GIS-based approach for potential analysis of solar PV generation at the regional scale: a case study of Fujian Province. Energy Policy 58:248-259 
77. Taubenböck H, Kraff N (2014) The physical face of slums: a structural comparison of slums in Mumbai, India, based on remotely sensed data. J Hous Built Environ 29(1):15-38

78. Taubenböck H et al (2009) Urbanization in India-spatiotemporal analysis using remote sensing data. Comput Environ Urban Syst 33(3):179-188

79. Trochta JT et al (2015) Remote sensing of physical cycles in Lake Superior using a spatio-temporal analysis of optical water typologies. Remote Sens Environ 171:149-161

80. United Nations (2014) World urbanization prospects: the 2014 revision. Pop. Division, Department of Economic and Social Affairs, UN, New York

81. Van de Voorde T et al (2011) Mapping form and function in urban areas: an approach based on urban metrics and continuous impervious surface data. Landsc Urban Plan 102(3):143-155

82. Van Der Meer F et al (2014) Geologic remote sensing for geothermal exploration: a review. Int J Appl Earth Obs Geoinf $33: 255-269$

83. Vermeiren K et al (2012) Urban growth of Kampala, Uganda: pattern analysis and scenario development. Landsc Urban Plan 106(2):199-206

84. Walsh-Thomas JM et al (2012) Further evidence of impacts of large-scale wind farms on land surface temperature. Renew Sustain Energy Rev 16(8):6432-6437

85. Wang $\mathrm{C}$ et al (2013) Air quality evaluation on an urban scale based on MODIS satellite images. Atmos Res 132:22-34

86. Wang S, Koch B (2010) Determining profits for solar energy with remote sensing data. Energy 35(7):2934-2938

87. Wang W-W et al (2003) Analysis on the spatial distribution variation characteristic of urban heat environmental quality and its mechanism. Chin Geogr Sci 13(1):39-47

88. Weber C, Puissant A (2003) Urbanization pressure and modeling of urban growth: example of the Tunis metropolitan area. Remote Sens Environ 86(3):341-352
89. Weeks JR et al (2007) Can we spot a neighborhood from the air? Defining neighborhood structure in Accra, Ghana. GeoJournal 69(1-2):9-22

90. Weng Q et al (2007) Assessing the effects of land use and land cover patterns on thermal conditions using landscape metrics in city of Indianapolis, United States. Urban Ecosyst 10(2):203-219

91. Wu C et al (2016) A scene change detection framework for multitemporal very high resolution remote sensing images. Signal Process 124:184-197

92. Xian G, Crane M (2005) Assessments of urban growth in the Tampa Bay watershed using remote sensing data. Remote Sens Environ 97(2):203-215

93. Xiao $J$ et al (2006) Evaluating urban expansion and land use change in Shijiazhuang, China, by using GIS and remote sensing. Landsc Urban Plan 75(1-2):69-80

94. Xie $\mathrm{Y}$ et al (2015) Population estimation of urban residential communities using remotely sensed morphologic data. IEEE Geosci Remote Sens Lett 12(5):1111-1115

95. Yang X, Liu Z (2005) Use of satellite-derived landscape imperviousness index to characterize urban spatial growth. Comput Environ Urban Syst 29(5):524-540

96. Yu XJ, Ng CN (2007) Spatial and temporal dynamics of urban sprawl along two urban-rural transects: a case study of Guangzhou, China. Landsc Urban Plan 79(1):96-109

97. Yuan F et al (2005) Land cover classification and change analysis of the twin cities (Minnesota) metropolitan area by multitemporal Landsat remote sensing. Remote Sens Environ 98(2-3):317-328

98. Zhang H, Lin H (eds) (2015) Feature selection for urban impervious surfaces estimation using optical and SAR images. In: 2015 joint urban remote sensing event (JURSE). 30 March 2015-1 April 2015

99. Zhang P et al (2016) Change detection based on deep feature representation and mapping transformation for multi-spatial-resolution remote sensing images. ISPRS J Photogr Remote Sens 116:24-41 